\title{
Contribution of Macrophages to Enhanced Regenerative Capacity of Dorsal Root Ganglia Sensory Neurons by Conditioning Injury
}

\author{
Min Jung Kwon, ${ }^{1,3}$ Jinha Kim, ${ }^{1,3}$ Haeyoung Shin, ${ }^{1,3}$ Soo Ryeong Jeong, ${ }^{1}$ Young Mi Kang, ${ }^{1}$ Jun Young Choi, ${ }^{1,2,3}$ \\ Dong Hoon Hwang, ${ }^{1,3}$ and Byung Gon Kim ${ }^{1,2,3}$ \\ ${ }^{1}$ Brain Disease Research Center, Institute for Medical Sciences and 2Department of Neurology, Ajou University School of Medicine, Suwon, 443-721, \\ Republic of Korea and ${ }^{3}$ Neuroscience Graduate Program, Department of Biomedical Sciences, Ajou University Graduate School of Medicine, Suwon, \\ 443-721, Republic of Korea
}

\begin{abstract}
Although the central branches of the dorsal root ganglion (DRG) sensory neurons do not spontaneously regenerate, a conditioning peripheral injury can promote their regeneration. A potential role of macrophages in axonal regeneration was proposed, but it has not been critically addressed whether macrophages play an essential role in the conditioning injury model. After sciatic nerve injury (SNI) in rats, the number of macrophages in DRGs gradually increased by day 7. The increase persisted up to $28 \mathrm{~d}$ and was accompanied by upregulation of inflammatory mediators, including oncomodulin. A macrophage deactivator, minocycline, reduced the macrophage number and expressions of the inflammatory mediators. Molecular signatures of conditioning effects were abrogated by minocycline, and enhanced regenerative capacity was substantially attenuated both in vitro and in vivo. Delayed minocycline infusion abrogated the SNI-induced long-lasting heightened neurite outgrowth potential, indicating a role for macrophages in the maintenance of regenerative capacity. Intraganglionic cAMP injection also resulted in an increase in macrophages, and minocycline abolished the cAMP effect on neurite outgrowth. However, conditioned media (CM) from macrophages treated with cAMP did not exhibit neurite growth-promoting activity. In contrast, CM from neuron-macrophage cocultures treated with cAMP promoted neurite outgrowth greatly, highlighting a requirement for neuron-macrophage interactions for the induction of a proregenerative macrophage phenotype. The growth-promoting activity in the $\mathrm{CM}$ was profoundly attenuated by an oncomodulin neutralizing antibody. These results suggest that the neuron-macrophage interactions involved in eliciting a proregenerative phenotype in macrophages may be a novel target to induce long-lasting regenerative processes after axonal injuries in the CNS.
\end{abstract}

\section{Introduction}

Traumatic spinal cord injury (SCI) disrupts axonal connections between the brain and the spinal motor centers. In general, functional recovery after SCI is limited primarily because of a lack of spontaneous axonal regeneration in the CNS (Schwab, 2002; Cafferty et al., 2008). However, there are a few conditions in which CNS axon regeneration can be achieved with relatively simple manipulations. The most representative example is the finding that the regeneration of dorsal root ganglion (DRG) sensory ax-

Received Jan. 21, 2013; revised Aug. 12, 2013; accepted Aug. 12, 2013.

Author contributions: M.J.K. and B.G.K. designed research; M.J.K., J.K., H.S., S.R.J., Y.M.K., J.Y.C., and D.H.H. performed research; M.J.K. and B.G.K. analyzed data; M.J.K. and B.G.K. wrote the paper.

This work was supported by National Research Foundation of Korea Grants 2012R1A2A2A01013143 and 2012R1A5A2051429 (MRC) and 2009-0081467 funded by the Korean government (Ministry of Science, ICT, and Future Planning) and Korean Health Technology R\& D Project, Ministry for Health, Welfare, and Family Affairs Grants A101663 (D.H.H.) and A101565 (J.Y.C.). We thank Drs. Benowitz and Yin at Harvard Medical School (Boston, MA) for providing neutralizing antibody against oncomodulin and relevant discussions. We also thank to Dr. Henzl at University of Missouri (Columbia, MO) for the permission to use a precious reagent developed from his laboratory.

The authors declare no competing financial interests.

Correspondence should be addressed to Dr. Byung G. Kim, Brain Disease Research Center, Institute for Medical Sciences, and Department of Neurology, Ajou University School of Medicine, Suwon 443-721, Korea. E-mail: kimbg@ajou.ac.kr.

DOI:10.1523/JNEUROSCI.0278-13.2013

Copyright $\odot 2013$ the authors $\quad 0270-6474 / 13 / 3315095-14 \$ 15.00 / 0$ ons through injured spinal cord is enhanced if a conditioning injury of peripheral branches is performed several days before the central lesion (Richardson and Issa, 1984; Neumann and Woolf, 1999). A more recent study demonstrated that DRG neurons acquire an enhanced regenerative phenotype even when the conditioning injury is performed after the central lesion and, more interestingly, that the conditioning effects can persist for as long as several months (Ylera et al., 2009). Although cAMP and other molecules have been proposed as key mediators of the conditioning effects (Cafferty et al., 2001, 2004; Cai et al., 2002; Qiu et al., 2005; Zou et al., 2009; Hollis and Zou, 2012), the precise mechanism of enhanced axon regeneration by conditioning injury and, in particular, the mechanisms mediating long-term maintenance of the conditioning effects remain elusive.

Another example of successful CNS axon regeneration is optic nerve regeneration after lens injury (Leon et al., 2000). In this model, the lens injury induces macrophage infiltration into the retina and macrophage-derived inflammatory factors are thought to enhance the regenerative capacity of retinal ganglion cell axons (Yin et al., 2003). Oncomodulin has been identified as a principal macrophage-derived molecule to mediate axon regeneration (Yin et al., 2006), although in vivo requirement of 
oncomodulin or macrophages for the lens injury-induced enhancement of axon regeneration is under debate (Hauk et al., 2008; Yin et al., 2009). Intriguingly, the possibility of involvement of inflammatory reactions in the conditioning effects of peripheral nerve lesion on DRG sensory neurons has also been suggested. Peripheral nerve injury induces an increase in the number of inflammatory cells, including macrophages in DRGs (Lu and Richardson, 1993). Triggering inflammation close to DRG cell bodies enhances axon regeneration after dorsal root crush injury (Lu and Richardson, 1991; Steinmetz et al., 2005). However, the extent to which macrophages and inflammatory reactions play mechanistic roles in conditioning injury-induced enhancement of axon regeneration capacity in DRG neurons has not been critically addressed. Hence, the present study tested the hypothesis that macrophages and inflammatory reactions contribute to enhanced DRG sensory axon regeneration by conditioning peripheral nerve injury. The results in this study indicated that macrophages and inflammatory reactions in DRGs play essential roles in maintaining conditioning- or cAMP-induced enhanced regenerative capacity. Furthermore, we provide evidence that neuron-macrophage interactions are required for acquisition of a proregenerative phenotype in macrophages.

\section{Materials and Methods}

Animals and surgical procedures. Adult female Sprague Dawley rats (250-300 g) were used in this study. All animal protocols were approved by the Institutional Animal Care and Use Committee of Ajou University School of Medicine. Animals were anesthetized with chloral hydrate $(400 \mathrm{mg} / \mathrm{kg}$, i.p.) during all of the surgical procedures. Sciatic nerve injury (SNI) was performed by transecting the right sciatic nerve 1,3 , and $7 \mathrm{~d}$ before fixation (immunofluorescence staining) or removal of DRGs (neurite outgrowth assays) or $7 \mathrm{~d}$ before spinal cord dorsal hemisection (in vivo regeneration assays). Briefly, a primary longitudinal cut was made in the skin overlying the femur of the right hindlimb. After the thigh muscles were exposed, surgical scissors with a blunt tip were inserted between the muscles to expose the sciatic nerve. The sciatic nerve was ligated proximal to its trifurcation and cut below the ligation site with fine surgical scissors. To create a dorsal column lesion in the spinal cord, a dorsal laminectomy was performed at the T9 level to expose the thoracic spinal cord. After the dura was opened with a midline incision, bilateral dorsal columns with adjacent lateral columns were cut out with iridectomy scissors inserted to a depth of $\sim 1.5 \mathrm{~mm}$. To ensure complete disruption of the dorsal column, a vacuum suction was applied to remove tissue debris remnants, and a hollow space was created between the proximal and distal lesion border. A small piece of Gelfoam pledget was temporarily placed over the lesion site to prevent bleeding. The overlying muscles and fascia were sutured in layer, and the skin was stapled. For visualization of regenerating dorsal column axons, $2 \mu \mathrm{l}(0.1 \%$ in PBS) of unconjugated cholera toxin subunit B (CTB; List Biological Laboratories) was injected into the proximal stump of the transected sciatic nerve $3 \mathrm{~d}$ before the animals were killed. For intraganglionic injection of the cAMP analog dibutyryl-
cAMP (db-cAMP; Calbiochem), the L5 dorsal lamina was removed, and $2 \mu \mathrm{l}$ of db-cAMP (100 mM in PBS) was injected into the L5 DRG at a rate of $0.5 \mu \mathrm{l} / \mathrm{min}$ using a Hamilton syringe configured with a micropipette.

In vivo minocycline administration. Minocycline was administered to DRGs using Alzet osmotic minipumps (Durect) inserted intrathecally at the time of SNI. The polyethylene tubing (PE-10) was advanced below the L6/S1 vertebral bone on the right side. The catheter was slightly heated so that it could be bent to position the tubing tip exactly at the L5 DRG. The catheter position was secured with sutures tied to L6/S1 bone. The osmotic minipump was also sutured to the paravertebral muscle. The exact positioning of the tubing tip was confirmed at the time the animals were killed. The pumps delivered minocycline ( $50 \mu \mathrm{g} / \mu \mathrm{l}$; Sigma) or PBS (to control for catheter-related variables) at a rate of $1 \mu \mathrm{l} / \mathrm{h}$ continuously for $7 \mathrm{~d}$. A pilot experiment found a concentration of $50 \mu \mathrm{g} / \mu \mathrm{l}$ minocycline to be the most effective in suppressing macrophage infiltration without toxicity. In a separate set of experiments, macrophages were deactivated between 21 and $28 \mathrm{~d}$ after SNI, and minocycline pumps were installed on day 21 after SNI.

Tissue processing and immunohistochemistry. Rats were anesthetized with an overdose of chloral hydrate and perfused with heparinized PBS, followed by $4 \%$ paraformaldehyde (PFA) in $0.2 \mathrm{M}$ phosphate buffer. DRGs or spinal cord tissues containing the lesion site were dissected and postfixed in $4 \%$ PFA for $2 \mathrm{~h}$, followed by cryoprotection in a graded series of sucrose solutions. DRGs were cryosectioned at $20 \mu \mathrm{m}$ thickness. For spinal cord tissue, parasagittal cryosections (at $20 \mu \mathrm{m}$ thickness) were 

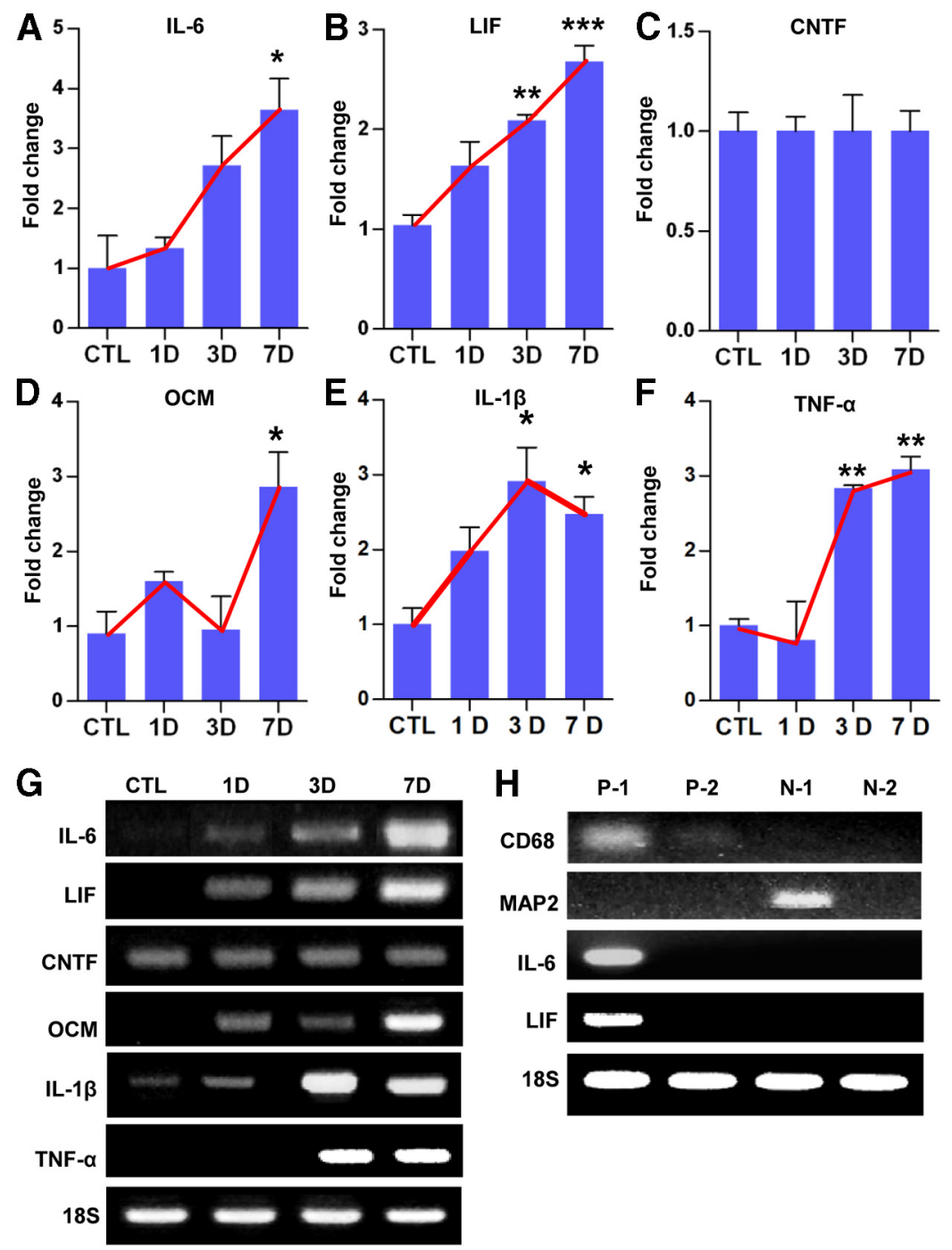

Figure 2. Expression of inflammatory mediators in DRGs after SNI. Quantification graphs of real-time RT-PCR for IL-6 $(\boldsymbol{A})$, LIF $(\boldsymbol{B})$, CNTF (C), oncomodulin (OCM) (D), IL-1 $\beta(\boldsymbol{E})$, and TNF- $\alpha(\boldsymbol{F})$. DRG samples were obtained before [control (CTL)] and 1,3, and $7 \mathrm{~d}$ after SNI. Red lines were drawn to emphasize temporal patterns of gene expression changes. $n=4$ animals for each time point. ${ }^{*} p<0.05$, ${ }^{* *} p<0.01$, and ${ }^{* * *} p<0.001$ compared with control values by one-way ANOVA, followed by Tukey's post hoc analysis. $\mathbf{G}$, Representative images of electrophoresed RT-PCR products. $18 \mathrm{~S}$ rRNA was used as an internal reference. $\boldsymbol{F}$, Representative RT-PCR analysis of inflammatory gene expression from DRG cell fractions separated by MACS. L4 and L5 DRGs ipsilateral to the SNI site were freshly dissected at $7 \mathrm{~d}$ and dissociated. CD68-positive macrophages were isolated in the P-1 (first) and P-2 (second) fractions. CD68-negative cells were collected in the $\mathrm{N}-1$ (first) and $\mathrm{N}-2$ (second) fractions. MAP2 gene expression was examined to verify the presence of neuronal cells in the CD68-negative fractions (N-1 and N-2). IL-6 and LIF mRNA were found only in the CD68-positive fraction. Two independent experiments showed similar results.

made in a 1:10 series. Tissue sections were mounted onto Super Frost plus slides (Thermo Fisher Scientific) and stored at $-20^{\circ} \mathrm{C}$ until use. For immunohistochemistry, tissue sections were treated with $10 \%$ normal goat serum and $0.3 \%$ Triton $\mathrm{X}-100$ for $1 \mathrm{~h}$, and then the primary antibodies, dissolved in the same blocking solution, were applied at $4^{\circ} \mathrm{C}$ overnight. The primary antibodies were mouse anti-ED1 (1:500; Serotec), rabbit anti-Iba1 (1:500; Wako Chemicals), rabbit anti-GAP-43 (1: 500; Millipore), mouse anti-Pan neurofilament (1:400; Covance), and goat anti-CTB antibodies (1:10,000; List Biological Laboratories). Tissue sections were washed thoroughly and then incubated with appropriate secondary antibodies tagged with Alexa Fluor 488 or 594 (1:500; Invitrogen) for $1 \mathrm{~h}$ at room temperature. For visualization of the CTB tracing signal, biotinylated anti-goat IgGs (Vector Laboratories) were applied after primary antibody incubation, and then spinal cord tissue sections were incubated with Alexa Fluor 594 streptavidin conjugates (Invitrogen). The coverslips were mounted onto slides with glycerol-based mounting medium (Biomeda). The images were taken using a FV 300 confocal microscope (Olympus Optical).

Quantitative RT-PCR. Total RNAs were extracted from DRGs using Trizol (Invitrogen) according to the protocol of the manufacturer. The amount of RNA was determined using spectroscopy at $260 \mathrm{~nm}$. Two micrograms of RNA were reverse transcribed to cDNA using a standard RT protocol. One microliter of cDNA was added to PCR reaction premix (GenDEPOT) with $10 \mathrm{pm}$ corresponding primer pairs. The following primers were used for PCR: $18 \mathrm{~S}$ rRNA, 5' -CGGCTACCACATCCAAGGAA-3' (forward) and 5'-TGCTGGCACCAGACTTGCCC TC-3' (reverse); IL-6, 5' -ATATGTTCTCAGGG AGATCTTGGAA-3' (forward) and 5'-GTGCAT CATCGCTGTTCATACA-3' (reverse); IL- $1 \beta$, 5' -TCTGTGACTCGTGGGATGAT-3' (forward) and 5'-GGCAGCCTTGTCCCTTGA-3' (reverse); TNF- $\alpha, 5^{\prime}$-GCCACCACGCTCTTCT GT-3' (forward) and 5'-GGCAGCCTTGTCCC TTGA-3' (reverse); leukemia inhibitory factor (LIF), 5' -TCAACTGGCTCAACTCAACG-3' (forward) and 5'-ACCATCCGATACAGCTCG AC-3' (reverse); ciliary neurotrophic factor (CNTF), 5'-CACCCCAACTGAAGGTGACT-3' (forward) and 5'-ACCTTCAAGCCCCATAGC TT-3' (reverse); oncomodulin, 5' -AGGCGTGA CTGCAGAAGAAT-3' (forward) and 5'-ACTT GGCTGGCAGACATCTT-3' (reverse); BDNF, 5'-GGGTGAAACAAAGTGGCTGT-3' (forward) and $5^{\prime}$-ATGTTGTCAAACGGCACA AA-3' (reverse); neurotrophin-3 (NT-3), 5'-GA TCCAGGCGGATATCTTGA-3' (forward) and 5' -AGCGTCTCTGTTGCCGTAGT-3' (reverse); and NGF, 5' -CCTGCCAGAGTCCTTT TCTG-3' (forward) and 5'-GGTTCAGGCCAC AAAGTGTT-3' (reverse). Quantitative realtime PCR was performed according to the protocol supplied by the Applied Biosystems SYBR Green PCR kit using the 7500 Real-Time PCR System (Applied Biosystems). Cycling conditions were $94^{\circ} \mathrm{C}$ for $30 \mathrm{~s}, 55-64^{\circ} \mathrm{C}$ for $31 \mathrm{~s}$, and $72^{\circ} \mathrm{C}$ for $60 \mathrm{~s}$ with a total of 34 cycles. Melting curves were generated after the last extension step, and the cycle threshold values were quantified by the Applied Biosystems 7500 software. Target gene expression was normalized in relation to expression of $18 \mathrm{~S}$ rRNA as an internal control.

Magnetic-activated cell sorting for isolation of macrophages. SNI was inflicted, and, $7 \mathrm{~d}$ after injury, animals were anesthetized with chloral hydrate and perfused intracardially with cold PBS. L4 and L5 DRGs ipsilateral to the injury site were dissociated in DMEM (HyClone). Cells were centrifuged at $1500 \mathrm{rpm}$ for $3 \mathrm{~min}$ at $4^{\circ} \mathrm{C}$ and washed with magnetic-activated cell sorting (MACS) buffer (0.5\% BSA, 2 mM EDTA containing PBS without divalent ions, $\mathrm{pH}$ 7.2). Cell suspensions were incubated for $15 \mathrm{~min}$ on ice with biotin-conjugated primary antibodies against CD68 (1:100; Abcam), which is found in the cytoplasmic granules of the cells in the macrophage lineage, and then incubated with avidinconjugated microbeads (Miltenyi Biotec) for $10 \mathrm{~min}$ on ice. Then, cell suspensions were allowed to flow through the minicolumn of the MACS Cell Separation kit (Miltenyi Biotec). The flow-through was collected as CD68-negative cells. Unbound cells remaining in the column were washed again with MACS buffer and collected as the second negative fraction. CD68-positive cells adsorbed to the minicolumn were separated using $500 \mu \mathrm{l}$ of elution buffer. A second round of elution was performed 
to collect the remaining CD68 cells and labeled as the second positive fraction. The second positive and negative fractions were used as controls to demonstrate effective cellular separation using the MACS system. Total RNA was extracted from each fraction using the methods described above.

ELISA. L4 and L5 DRGs were dissected and lysed, and cAMP was measured immediately using a cAMP enzyme immunoassay kit (Assay Designs), according to the protocol of the manufacturer. In each well, $100 \mu$ l of DRG lysate at a concentration of $20 \mu \mathrm{g} / \mu \mathrm{l}$ was used. Each experiment was performed in triplicate and repeated three times. Concentration of oncomodulin in the conditioned medium (CM) was measured using an ELISA kit for rat oncomodulin (catalog \#MBS908312; Mybiosource), according to the protocol of the manufacturer. One hundred microliters of $\mathrm{CM}$ were used in each well. Three cultures were performed to collect CM for each condition, and each $\mathrm{CM}$ was measured in triplicate.

Primary culture of dissociated adult DRG neurons. Adult DRGs at the fourth and fifth lumbar spinal cord were freshly dissected and treated with $125 \mathrm{U} / \mathrm{ml}$ type XI collagenase (Sigma) dissolved in DMEM (HyClone) for $90 \mathrm{~min}$ at $37^{\circ} \mathrm{C}$ with gentle rotation. After washing five times with DMEM, the cells were dissociated by trituration using a pipette tip and centrifuged at $1500 \mathrm{rpm}$ for $3 \mathrm{~min}$. Cell pellets were resuspended in Neurobasal-A (Invitrogen) supplemented with B-27 (Invitrogen) and plated onto eight-well culture slides (BD Biosciences) precoated with $0.01 \%$ poly-D-lysine (Sigma) and $3 \mu \mathrm{g} / \mathrm{ml}$ laminin (Invitrogen). It has been reported that the extent of neurite outgrowth from dissociated rat DRG sensory neurons is minimal for the initial $18 \mathrm{~h}$ in culture (Cafferty et al., 2004). In our experiments, the culture duration was strictly confined to $15 \mathrm{~h}$ to minimize neurite outgrowth in control conditions (without conditioning injury). Neurite outgrowth was visualized by immunostaining with mouse anti- $\beta$ III-tubulin (1:1000; Promega), followed by Alexa Fluor 594-conjugated anti-mouse secondary antibody.

Primary macrophage culture and neuron-macrophage coculture. Adult female Sprague Dawley rats (250-300 g) were anesthetized with an overdose of chloral hydrate. Immediately after killing the animals by a cervical dislocation, peritoneal macrophages were harvested by intraperitoneal lavage with $50 \mathrm{ml}$ of ice-cold PBS. The lavage fluid was centrifuged at $1500 \mathrm{rpm}$ for $10 \mathrm{~min}$ at $4^{\circ} \mathrm{C}$ to pellet the cells. The cell pellets were resuspended in $5 \mathrm{ml}$ of red blood cell (RBC) lysis buffer (Qiagen) for 3 min at room temperature and then washed three times using PBS. After the final wash, the cells were resuspended in RPMI-1640 (HyClone) supplemented with $10 \%$ fetal bovine serum (FBS), plated onto a $100 \mathrm{~mm}$ culture dish (BD Biosciences) precoated with $0.01 \%$ poly-D-lysine (Sigma), and maintained at $37^{\circ} \mathrm{C}$ in a humidified incubator with $5 \%$ $\mathrm{CO}_{2}$. Four hours after plating, the cultured macrophages were treated with db-cAMP $(100 \mu \mathrm{M})$ or zymosan $(12.5 \mu \mathrm{g} / \mathrm{ml})$ with or without minocycline $(10 \mu \mathrm{g} / \mu \mathrm{l})$ for $24 \mathrm{~h}$. Then, the culture medium was replaced with fresh DMEM supplemented with B-27 (Invitrogen). The cultures were maintained for $72 \mathrm{~h}$ without changing the medium, and the $\mathrm{CM}$ was collected, centrifuged at $1500 \mathrm{rpm}$ for $5 \mathrm{~min}$, and passed through a 0.2 $\mu \mathrm{m}$ filter (BD Biosciences) to remove any remaining cellular debris. Primary dissociated DRG neuron cultures were established as described above and maintained in culture for $2 \mathrm{~h}$ to allow for attachment to the culture dishes. Then, the medium was replaced with the collected CM. After $15 \mathrm{~h}$ in culture, the cells were fixed and immunostained for $\beta I I I-$ tubulin to visualize neurite outgrowth. For the neuron-macrophage coculture condition, neurons were incubated with DMEM (Invitrogen) supplemented with B-27 (Invitrogen) for $4 \mathrm{~h}$. After incubation, peritoneal macrophages were plated on top of neurons at a ratio of 1:5 (neurons/macrophages), followed by treatment with various manipulations $4 \mathrm{~h}$ after macrophage plating. The CM was collected as described above. Neuron-macrophage cocultures using cell culture inserts were performed by plating the neurons onto six-well plates first, followed by plating peritoneal macrophages on cell culture inserts (BD Biosciences) $4 \mathrm{~h}$ later. To neutralize the potential activities of IL-6, LIF, and oncomodulin in the collected CM, IL-6 $(20 \mu \mathrm{g} / \mathrm{ml}$; R\&D Systems), LIF (20 $\mu \mathrm{g} / \mathrm{ml}$; R\&D Systems), or oncomodulin $(20 \mu \mathrm{g} / \mathrm{ml}$; kindly provided by Dr. Benowitz, Harvard University, Boston, MA) neutralizing antibodies were added. Control cultures were treated with the same amount of goat or rabbit IgG (R\&D Systems).

Quantification of neurite outgrowth in culture, and macrophage cell number and axon regeneration in vivo. For the neurite outgrowth assays, the mean neurite length per neuron was measured to compare the extent of neurite outgrowth between different experimental conditions. Neurite length was measured using the Neuron J plugin for the image analysis software suite NIH Image J (publicly available from http://rsbweb.nih. gov/ij/index.html). This program facilitates tracing and quantification of elongated structures. Each experimental condition was replicated in four wells per culture. Each well was divided into four quadrants, and a $200 \times$ magnification image was obtained at the center of each quadrant (four images in each well). Neurites were traced for all neurons in each image, and the number of DRG neurons per image was counted. There were $\sim 20$ neurons per image, and, therefore $\sim 80$ neurons were measured for each well. The average neurite length per neuron in each well was calculated by dividing the total neurite length from $\sim 80$ neurons by the number of neurons. The values from the four wells were averaged for each culture, and average group values for neurite length per neuron were obtained by averaging values from three to four independent cultures.

To quantify macrophage infiltration into DRGs, the number of macrophages in DRGs was quantified in images of Ibal immunostained tissue sections taken at $200 \times$ magnification. Macrophages were counted in four images per animal, and the total numbers were divided by the area of the imaged DRG to obtain the macrophage counts per unit area. When an Iba1-positive macrophage was positioned close to a neurofilamentpositive DRG neuron without appreciable background signals between the two cells, the macrophage was regarded as being physically associated with the neuron. The number of macrophages showing the physical association was divided by the total number of macrophages in the same image to obtain the percentage of macrophages associated with DRG neurons.

To quantify the extent of dorsal column axon growth after injury, every 10th parasagittal spinal cord section $(200 \mu \mathrm{m}$ intersection interval) containing CTB tracing signals was used for analysis. Images of CTB staining were captured from $5 \mathrm{~mm}$ caudal to $5 \mathrm{~mm}$ rostral to the lesion site. After the caudal lesion border was identified using GFAP staining, lines perpendicular to the longitudinal axis were drawn at $100 \mu \mathrm{m}$ intervals from the lower lesion border to delineate counting blocks, with blocks named according to their shortest distance to the lesion border (for example, the number of axons between +100 and +200 was recorded as the value in the +100 block). The number of CTB positive axons between successive lines was counted and recorded as the number 

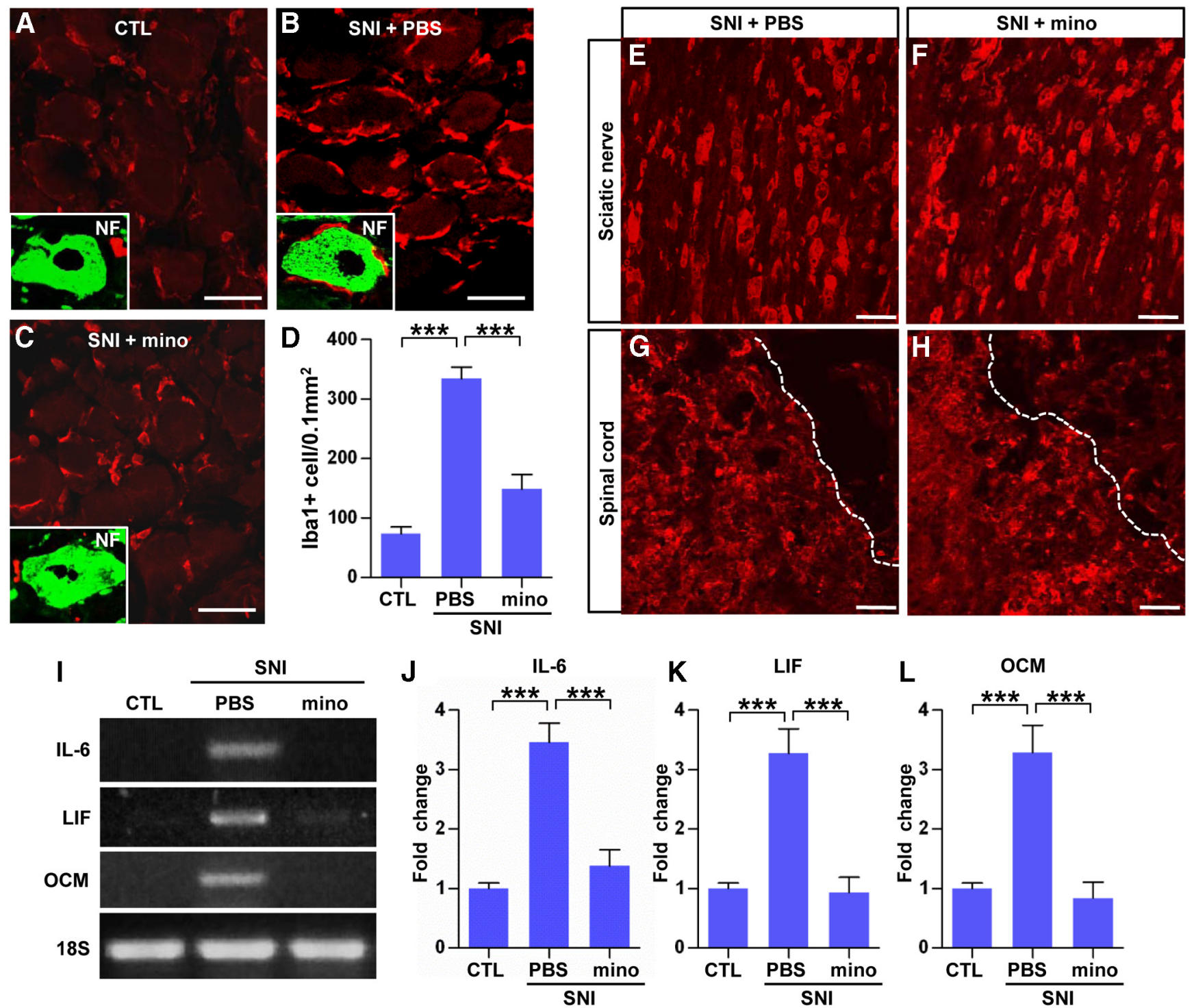

Figure 4. Minocycline infusion effectively decreased the number of macrophages and inflammatory gene expression in DRGs after SNI. A-C, Immunofluorescence images of DRG sections stained with Iba1 antibody. The animals received SNI, and osmotic minipumps were installed to infuse minocycline (mino; $50 \mu \mathrm{g} / \mu \mathrm{l}, 1 \mu \mathrm{l} / \mathrm{h} ; \boldsymbol{C}$ ) or PBS (B) for $7 \mathrm{~d}$. Control animals (CTL) also underwent surgery to have the PBS minipump installed without SNI. Inset figures in $A-C$ magnify one DRG neuron (stained with neurofilament, green) to show a physical relationship with adjacent Iba1-stained macrophages (red). $\boldsymbol{D}$, A quantification graph of the number of $\mathrm{lba1}$-positive macrophages in $L 5 \mathrm{DRGs}$ per $0.1 \mathrm{~mm}^{2} . n=4$ animals per group. Representative images of sciatic nerve $(\boldsymbol{E}, \boldsymbol{F})$ and spinal cord lesion site $(\boldsymbol{G}, \boldsymbol{H})$ sections stained with Iba1. Activation of macrophages in the sciatic nerve and spinal cord lesion site was comparable between $\operatorname{PBS}(\boldsymbol{E}, \boldsymbol{G})$ and mino infusion groups $(\boldsymbol{F}, \boldsymbol{H})$. Dotted lines in $\mathbf{G}$ and $\boldsymbol{H}$ indicate lesion borders. $I$, Representative bands of RT-PCR products for IL-6, LIF, and oncomodulin (OCM). L5 DRGs were obtained 7 dafter ipsilateral SNI and installation of minipump delivering PBS or minocycline. $\boldsymbol{J}, \boldsymbol{K}$, Comparison of mRNA levels of IL-6 $(\boldsymbol{J})$, LIF $(\boldsymbol{K})$, and $0 \mathrm{CM}(\boldsymbol{L})$ measured by quantitative RT-PCR. $n=5$ animals per group. ${ }^{* * *} p<0.001$ by one-way ANOVA, followed by Tukey's post hoc analysis. Scale bars, $50 \mu \mathrm{m}$.

of axons in the block. The values were averaged from the sections with visible axons in each animal. In addition, the longest distance of regenerating axons beyond the caudal lesion border was recorded for each animal.

Statistical analyses. All values are expressed as mean \pm SEM. Statistical comparison of mean values was performed using one-way ANOVA, followed by Tukey's post hoc tests. Repeated-measures two-way ANOVA was used to compare the axon number at different distances from the epicenter. Quantification graphs were generated using Prism version 5.00 (GraphPad Software).

\section{Results}

Macrophages and inflammatory cytokines in DRGs after SNI We examined whether the number of macrophages in DRGs increases after transection of the sciatic nerve (conditioning injury). In control DRGs without any injury, $\sim 30$ Iba1-positive macrophages per $0.1 \mathrm{~mm}^{2}$ were found close to the sensory neurons (Fig. 1A). At $1 \mathrm{~d}$ after SNI, there was no change in the number of macrophages (data not shown). Appreciable changes were noted by $3 \mathrm{~d}$ after SNI, when an average of $95 \pm 8.0$ macrophages were counted (Fig. $1 B, G$ ). At $7 \mathrm{~d}$, the number of macrophages sharply increased by 10 -fold compared with control DRGs (Fig. 1C,G). Sensory neurons were frequently found to be encircled by surrounding macrophages (Fig. $1 C$, inset), suggesting intimate neuron-macrophage interactions. The increases in the number of macrophages persisted without significant reduction at least until day 28, the last time point examined (Fig. $1 D, E, G)$. The dramatic increase of macrophage number by SNI was also confirmed using a different macrophage marker, ED1 (CD68) (Fig. 1F). 
Although an injury to the peripheral branches primes sensory neurons for enhanced axon regeneration, a similar injury to the central branches does not invoke a proregenerative response (Schreyer and Skene, 1993; Chong et al., 1994). Based on this, we reasoned that, if macrophage activation is related to conditioning effects, an injury to the central branches would not entail changes in macrophages. To test this, we performed an L5 dorsal rhizotomy and then examined the DRGs at $7 \mathrm{~d}$ after the injury to the central branch. In accordance with our expectations, the number of macrophages was significantly smaller than that after SNI and not significantly different from that in control DRGs (Fig. 1G,H).

We also tested whether the SNI-induced macrophage activation was accompanied by increased expression of inflammatory mediators. The gene expression of IL-6 and LIF, the members of the neuropoietic cytokine family known to be associated with sensory axon regeneration (Cafferty et al., 2001, 2004; Cao et al., 2006), increased with a time course similar to that of the increase in macrophage number (Fig. $2 A, B, G$ ). The level of IL-6 mRNAs showed a modest increase at $1 \mathrm{~d}$ but began to show a prominent change at $3 \mathrm{~d}$, reaching its maximum at $7 \mathrm{~d}$ (Fig. $2 A, G$ ). The expression of LIF showed a very similar pattern to that of IL-6 (Fig. $2 B, G$ ). However, another member of the neuropoietic cytokine family, CNTF, did not show any appreciable change (Fig. $2 C, G)$. We also examined the expression of the proinflammatory cytokines IL- $1 \beta$ and TNF- $\alpha$, recently associated with peripheral nerve regeneration (Nadeau et al., 2011), and found increased expressions with a similar time course to that of IL-6 and LIF (Fig. $2 E-G)$. More importantly, we observed an increased mRNA level of oncomodulin (Fig. $2 D, G$ ), which was identified as a macrophage-derived molecule sufficient to enhance optic nerve regeneration (Yin et al., 2006). The mRNA level of oncomodulin was three times that in control DRGs at $7 \mathrm{~d}$, when the number of macrophages peaked. To determine cellular sources of the inflammatory cytokines, CD68-positive macrophages were separated by MACS from dissociated DRG cells obtained at $7 \mathrm{~d}$ after SNI. As expected, CD68 mRNA expression was selectively observed in the CD68-positive fraction. In contrast, the neuronspecific marker MAP2 was expressed exclusively in the CD68negative fraction (Fig. $2 F$ ), indicating that the macrophages were successfully separated from the neuronal population. IL-6 and LIF mRNA expression was detected exclusively in the CD68positive fraction but not in the negative fraction, indicating that the primary source of the IL-6 and LIF production after SNI was the macrophages.

Macrophages can produce neurotrophins (Barouch et al., 2001), and it has been suggested that macrophage-derived neurotrophins contribute to sciatic nerve regeneration (Barrette et al., 2008). Therefore, we also examined the expression of neurotrophin mRNAs. BDNF and NT-3 gene expression gradually increased after SNI with a peak at $7 \mathrm{~d}$ (Fig. $3 A, B$ ), showing a similar time course to those of inflammatory mediators. The increase in NGF expression peaked at $3 \mathrm{~d}$ and maintained at $7 \mathrm{~d}$ after SNI (Fig. 3C).

\section{Minocycline infusion to the DRG effectively reduced the macrophage number and expression of inflammatory mediators}

To investigate a possible role for macrophages in the SNIinduced conditioning effects, we administered minocycline, a macrophage deactivator known to reduce macrophage activation in various experimental settings (Raghavendra et al., 2003; Yong et al., 2004; Arnold and Hagg, 2011; Ghanouni et al., 2012). Minocycline $(50 \mu \mathrm{g} / \mu \mathrm{l})$ or PBS was infused intrathecally for $7 \mathrm{~d}$ onto
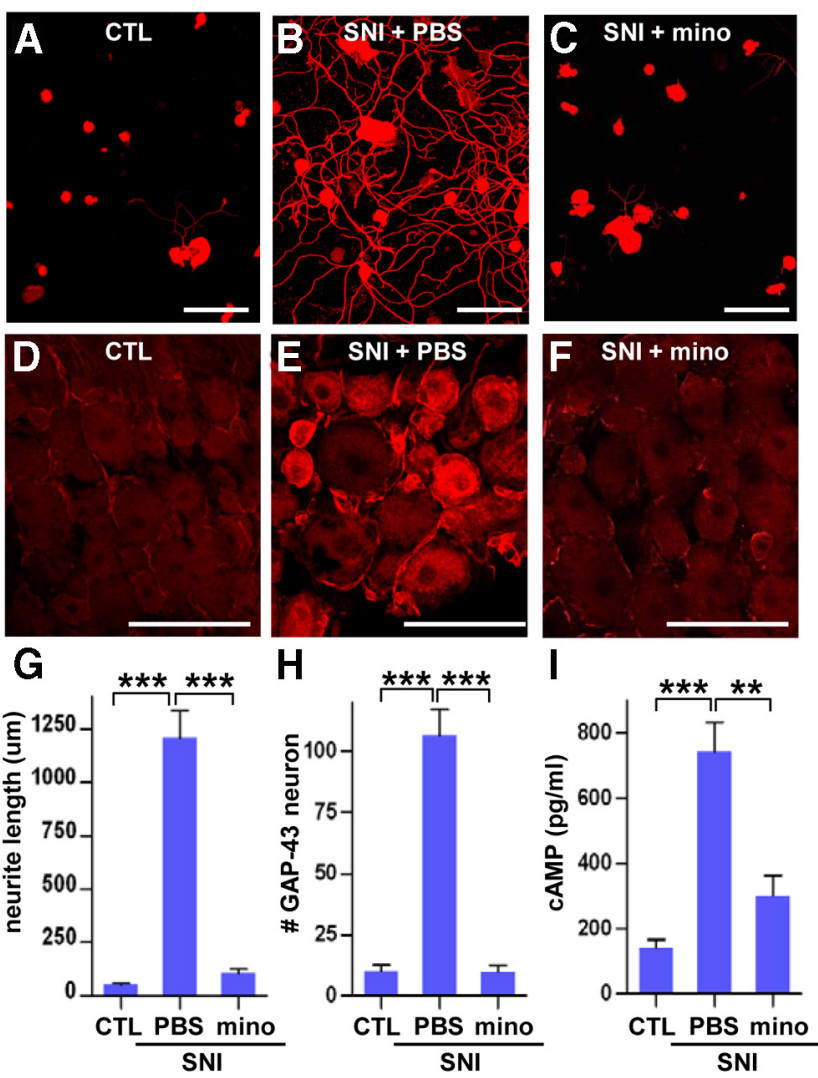

Figure 5. Minocycline prevented preconditioning SNI-induced increases in regenerative capacity. A-C, Neurite outgrowth of cultured DRGs without SNI [control (CTL); $A$ ] or after SNI with infusion of $P B S(B)$ or minocycline (mino; $C$ ) via osmotic minipumps for $7 \mathrm{~d}$. The culture duration was $15 \mathrm{~h}$. Scale bars, $100 \mu \mathrm{m}$. D, E, GAP-43 immunostaining of L5 DRGs without SNI (CTL; $\boldsymbol{D}$ ) or after SNI with infusion of PBS $(\boldsymbol{E})$ or mino $(\boldsymbol{F})$. Scale bars, $100 \mu \mathrm{m}$. $\boldsymbol{G}, \boldsymbol{H}$, Quantification of the mean neurite length per neuron $(\boldsymbol{G})$ in DRG cultures and the number of GAP-43-positive neurons per $0.1 \mathrm{~mm}^{2}$ in DRG tissue sections $(\boldsymbol{H}) . n=3$ independent experiments for neurite outgrowth assays, and $n=4$ animals per group for GAP-43 neuron counting. $I$, ELISA of cAMP levels in DRGs obtained at $7 \mathrm{~d}$ after injury. $n=4$ animals per group. ${ }^{* *} p<0.01$ and ${ }^{* * *} p<0.001$ by one-way ANOVA, followed by Tukey's post hoc analysis.

the L5 DRG using a small catheter connected to an osmotic minipump. This concentration of minocycline did not reduce the number of neurofilament-positive neurons or GFAP-positive satellite cells (data not shown). As expected, PBS infusion failed to affect the SNI-induced increase in macrophage number at $7 \mathrm{~d}$ after injury (Fig. $4 A, B$ ). In contrast, the minocycline infusion decreased the macrophage numbers by $>50 \%$ (Fig. $4 C, D$ ). Minocycline also affected the extent of physical contacts between macrophages and DRG neurons (Fig. $1 C$, inset). After SNI, the majority of macrophages $(75.5 \pm 1.4 \%)$ were found to contact DRG neurons (Fig. 4B, inset). Minocycline infusion reduced the percentage of macrophages abutting neurons to $35.8 \pm 1.2 \%$ (Fig. $4 C$, inset), which was essentially the same as that in control DRGs (without SNI, $35.4 \pm 1.7 \%$; Fig. $4 A$, inset). Macrophage activation in the sciatic nerve and spinal cord at the lesion site was examined to see whether the minocycline infusion influenced macrophages only in the DRGs without distant effects. We found that the density of Iba1-positive macrophages was not different between the PBS and minocycline infusion groups in these regions (Fig. 4E-H). We also examined whether minocycline reduced the expression of inflammatory mediators. Minocycline infusion almost completely abolished the SNI-induced increases in IL-6 and LIF mRNA levels (Fig. 4I-K). Furthermore, the level 

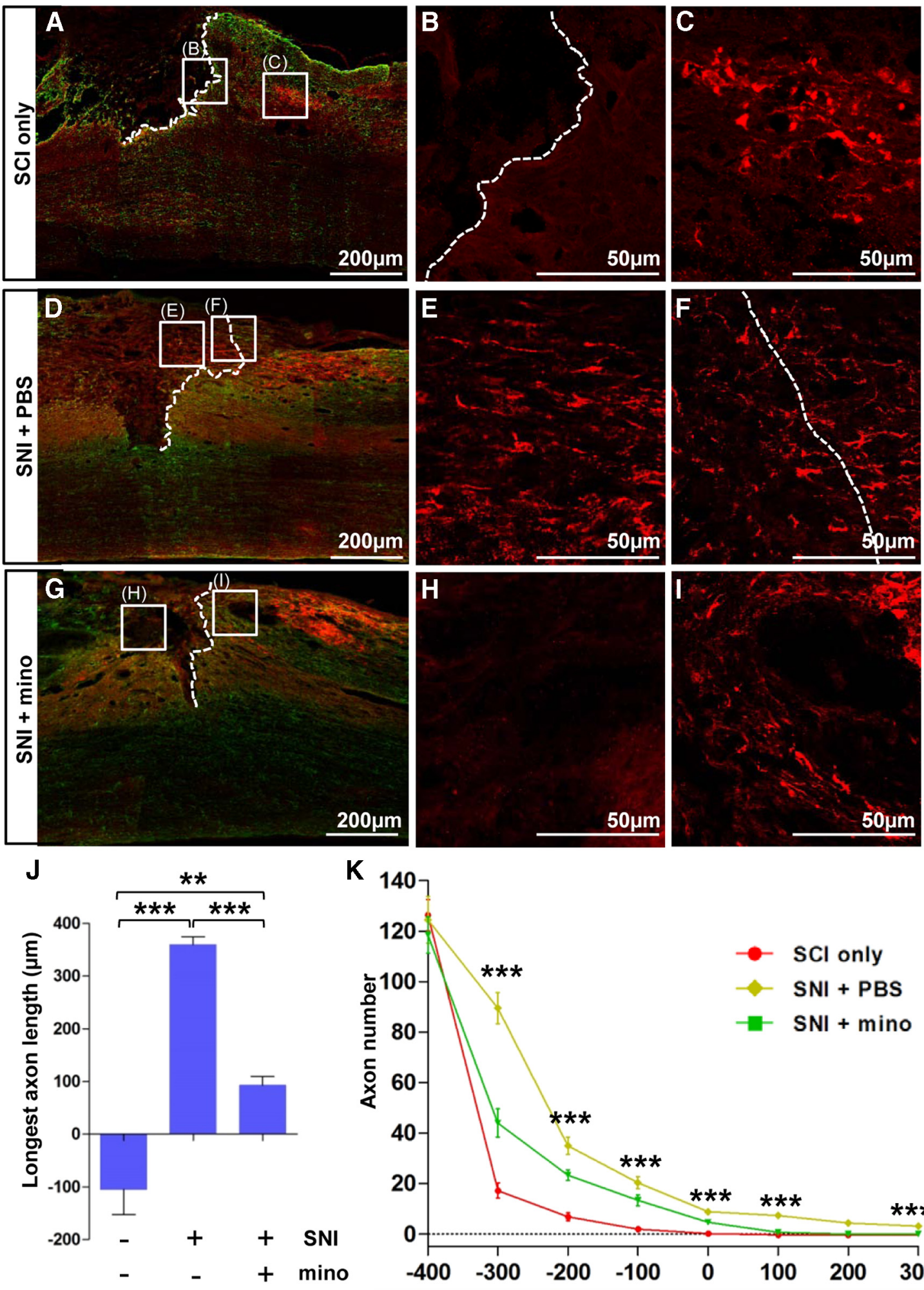

K 140

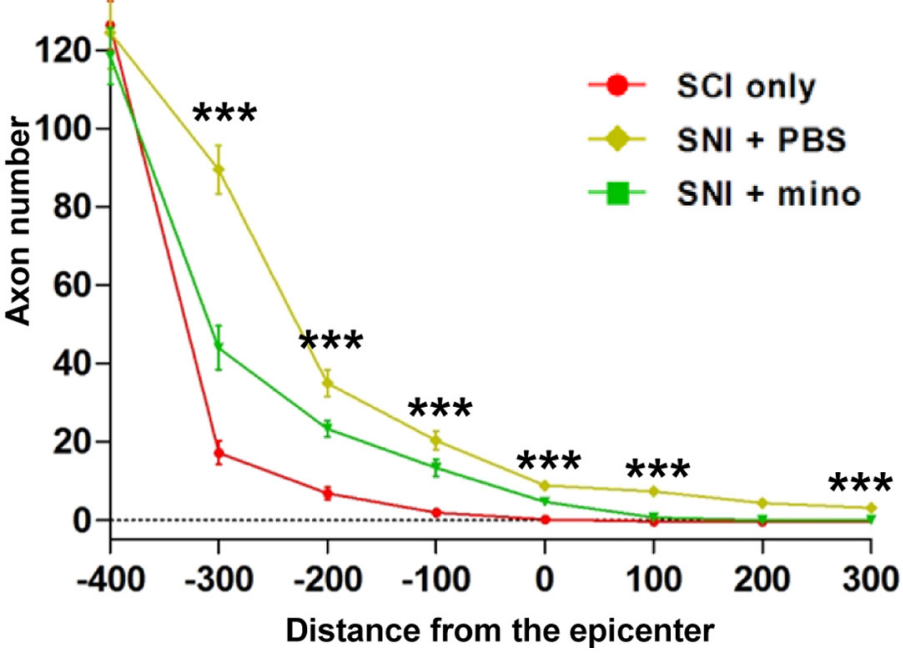

Figure 6. Minocycline decreased the extent of axon regeneration in vivo. A-I, Representative images of (TB ( $0.1 \%$ ) labeled axons (red) and GFAP (green) immunostained spinal cord sections from SCl only $(\boldsymbol{A}-\boldsymbol{C})$, preconditioning SNI with infusion of PBS (D-F), and SNI with infusion of minocycline (mino; $50 \mu \mathrm{g} / \mu \mathrm{l}, 1 \mu \mathrm{l} / \mathrm{h}$ ) groups $(\mathbf{G}-\boldsymbol{I})$. SNI was inflicted at $7 \mathrm{~d}$ before dorsal hemisection SCl, and animals were killed 1 month after the SCI. Dashed lines indicate caudal lesion borders as determined by GFAP immunostaining. Boxed regions in $A, D$, and $G$ represent positions of magnified images $(\boldsymbol{B}, \boldsymbol{C}, \boldsymbol{E}, \boldsymbol{F}, \boldsymbol{H}, \boldsymbol{I})$. Dotted white lines represent distal lesion borders determined by GFAP immunostaining. $J$, A quantification graph of the mean longest axon length beyond the caudal lesion borders. ${ }^{* *} p<0.01$ and ${ }^{* * *} p<0.001$ by one-way ANOVA, followed by Tukey's post hoc analysis. $K$, A quantification graph of CTB-positive axon numbers at different distances from the epicenter. ${ }^{* * *} p<0.001$ by post hoc one-way ANOVA at each distance point. $n=6$ for each group for $J$ and $K$ analyses. 
of oncomodulin mRNA returned to baseline after minocycline infusion (Fig. 4I,L).

\section{Minocycline significantly attenuated the conditioning effects of SNI}

In the next set of experiments, we examined whether minocycline infusion affected the enhanced regenerative capacity of sensory neurons after preconditioning SNI. The sciatic nerve was transected, and either minocycline or PBS was infused onto the ipsilateral L5 DRG for $7 \mathrm{~d}$. Then, the L5 DRGs were freshly dissected and dissociated for neurite outgrowth assays. Most of the cultured DRG neurons without preconditioning SNI did not grow neurites by $15 \mathrm{~h}$ in culture (Fig. $5 A$ ). However, DRG neurons dissected $7 \mathrm{~d}$ after SNI grew numerous and elongated neurites within the same $15 \mathrm{~h}$ culture period (Fig. $5 B, G$ ). This enhanced neurite outgrowth by SNI was almost completely abolished by minocycline infusion (Fig. 5C,G). The minocycline-induced decrease in neurite growing capacity was accompanied by reduced levels of a regeneration associated protein, GAP-43 (Benowitz and Routtenberg, 1997). GAP-43 protein expression was significantly increased at $7 \mathrm{~d}$ after SNI (Fig. 5D,E,H), but minocycline abolished the SNI-induced GAP-43 expression (Fig. 5F,H). When we measured the level of cAMP in the DRGs as another marker of regenerative capacity (Fig. 5I), the average cAMP level in the DRGs without previous SNI was $142.6 \pm 24.3 \mathrm{pg} / \mathrm{ml}$. The cAMP level was increased by more than four times at $7 \mathrm{~d}$ after SNI. Notably, minocycline infusion for $7 \mathrm{~d}$ after SNI significantly decreased the cAMP level.

We also studied the effects of minocycline on conditioning effects of SNI in vivo. The sciatic nerve was transected, and either minocycline or PBS was infused onto the ipsilateral L5 DRG for $7 \mathrm{~d}$. Then, the dorsal spinal cord was hemisected at the T7 level, and sensory axon regeneration was examined 1 month later. Without preconditioning SNI, injured axons retracted a few hundred micrometers away from the caudal end of the injury site (as determined by GFAP staining; Fig. 6A-C). Preconditioning SNI at $7 \mathrm{~d}$ before the spinal cord hemisection completely prevented the axon retraction and promoted axonal growth beyond the caudal injury border (SNI + PBS; Fig. 6D-F). Minocycline infusion abrogated the axonal growth beyond the caudal injury border (Fig. 6G-I). In the minocycline infusion group (SNI + mino), CTB-traced sensory axons seemed to end very close to the caudal injury border, indicating that axon retraction was prevented by SNI even after the minocycline infusion. The length of the longest axon $(359.5 \pm 15.5)$ was significantly larger in the $\mathrm{SNI}+\mathrm{PBS}$ group than in the control or SNI + mino groups (Fig. $6 J)$. Counting axon numbers at different distances showed more axons at all distances in SNI + PBS than in the other groups (Fig. $6 K)$. Axon numbers in the SNI + mino group were also apparently higher than those in the injury-only group from caudal regions $(-300,-200,-100 \mu \mathrm{m})$ up to the epicenter $(0 \mu \mathrm{m})$. Repeated-measures two-way ANOVA revealed a significant difference in CTB-traced axon number across the different distances between the groups $(p<0.001)$.

To rule out the possibility that minocycline directly influences axonal growth, DRG neurons were cultured with minocycline at various concentrations for $24 \mathrm{~h}$ (a sufficiently long culture period to observe growth of unconditioned DRG neurons). Minocycline did not reduce the neurite outgrowth even at $12.5 \mu \mathrm{M}$ (the highest concentration that could be used without cytotoxicity; Fig. 7).
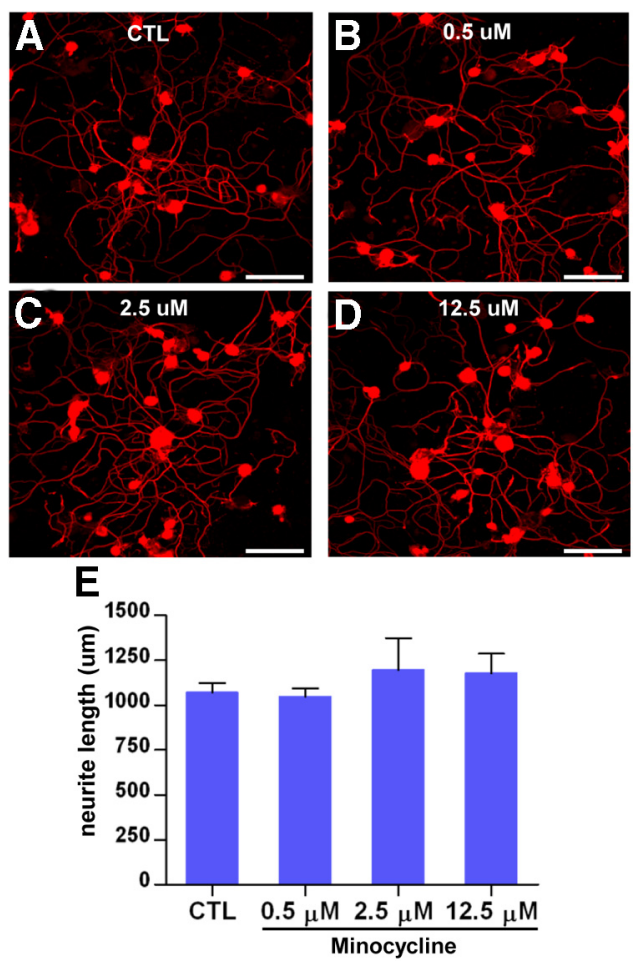

Figure 7. Minocycline has no direct effect on neurite outgrowth. $\boldsymbol{A}-\boldsymbol{D}$, Adult DRG neurons were cultured for $24 \mathrm{~h}$ with minocycline at $0(\boldsymbol{A}), 0.5(\boldsymbol{B}), 2.5(\boldsymbol{C})$, and $12.5(\boldsymbol{D}) \mu \mathrm{m}$ concentrations. Scale bars, $100 \mu \mathrm{m}$. $\boldsymbol{E}$, Quantification of the DRG neurite outgrowth assay with minocycline treatment. $n=4$ independent cultures for each condition. CTL, Control.

\section{Macrophages may play a role in maintaining enhanced regenerative capacity}

To investigate whether macrophages are required for the initiation of conditioning effects, minocycline was infused for 1 or $3 \mathrm{~d}$ after preconditioning SNI instead of $7 \mathrm{~d}$, and the extent of neurite outgrowth was compared with that in animals with PBS infusion for the same duration. Without preconditioning SNI, DRG neurons cultured for $15 \mathrm{~h}$ exhibited very little amount of neurite outgrowth (Fig. 8A). In cultures of DRG neurons isolated at $1 \mathrm{~d}$ after SNI with PBS infusion (Fig. $8 B$ ), a small percentage of neurons showed elongated neurites. A similar extent of neurite outgrowth was still observed with minocycline infusion for $1 \mathrm{~d}$ (Fig. $8 C, G)$, indicating that macrophages are not required for the initial manifestation of conditioning effects. Preconditioning SNI $3 \mathrm{~d}$ before dissociation greatly enhanced neurite outgrowth from most of the cultured neurons, and the extent of neurite outgrowth per neuron was almost comparable with that of DRG neurons cultured at $7 \mathrm{~d}$ after SNI (Fig. 8D,F). Minocycline infusion for the $3 \mathrm{~d}$ duration almost completely abrogated neurite outgrowth (Fig. $8 E, G$ ). This result suggests that, although macrophages are not required for the initiation, they may play an essential role in the full manifestation of conditioning effects. Because the increase in macrophage number persisted up to 1 month (Fig. $1 G$ ), we hypothesized that macrophages may play a role in maintaining enhanced growth capacity for a long period (Ylera et al., 2009). To directly address this, we performed experiments in which minocycline osmotic minipumps were installed on day 21, and DRGs were dissected on day 28 (a $7 \mathrm{~d}$ minocycline treatment; Fig. $8 H$ ). In the absence of minocycline, enhanced regenerative capacity was maintained until day 28 at a level comparable with that of DRG neurons cultured at $7 \mathrm{~d}$ after SNI (Fig. $8 I, J)$. Minocycline treatment begun at $21 \mathrm{~d}$ after SNI, when in- 

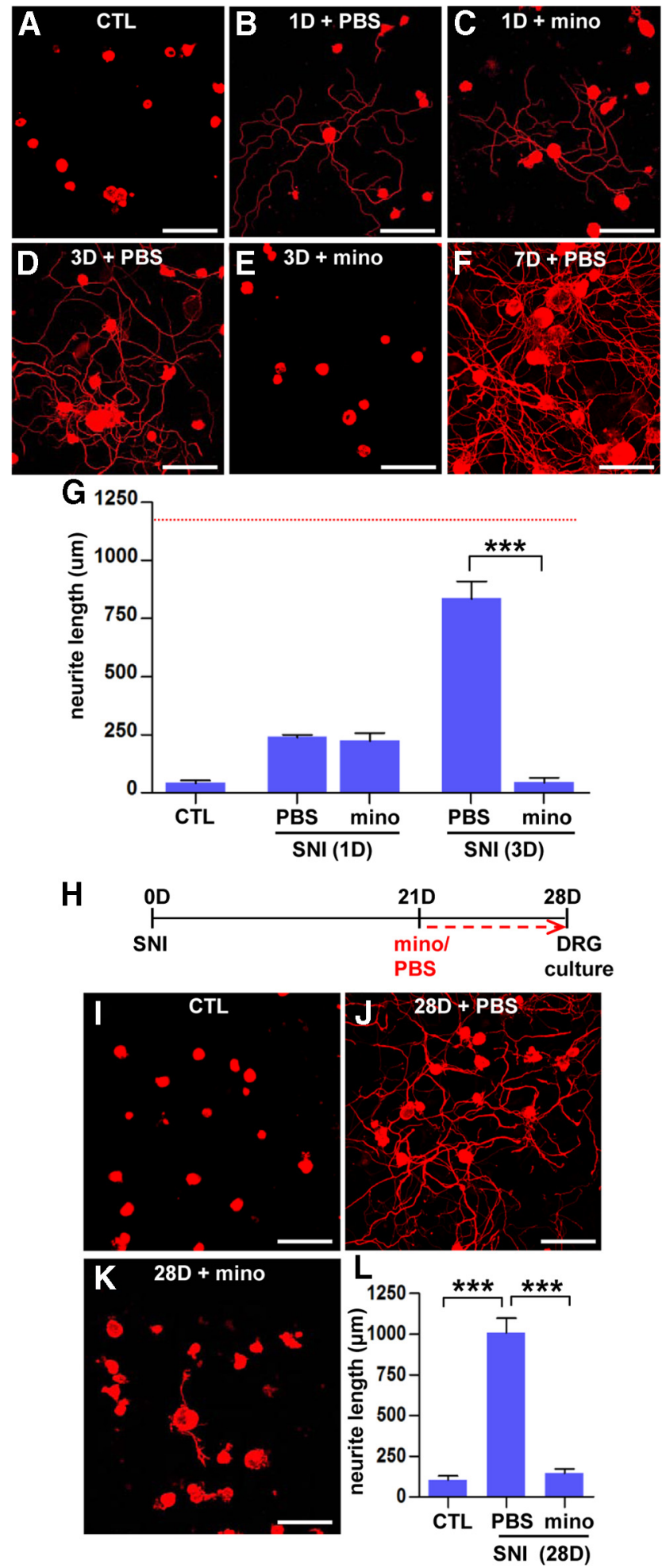

Figure 8. Macrophages may play a role in maintaining enhanced regenerative capacity. $\boldsymbol{A}-\boldsymbol{F}$, Representative images of $\beta$ III-tubulin-positive cultured DRG neurons. DRGs were freshly dissected from sham control (CTL; $\boldsymbol{A})$, animals at $1 \mathrm{~d}$ after preconditioning SNI with PBS $(\boldsymbol{B})$ or minocycline (mino; $\boldsymbol{C}$, and animals at $3 \mathrm{~d}$ after preconditioning SNI with PBS $(\boldsymbol{D})$ or minocycline $(\boldsymbol{E})$ and cultured for $15 \mathrm{~h}$. A representative image of cultured neurons isolated from animals at $7 \mathrm{~d}$ after preconditioning SNI with PBS (the same group of animals in Fig. $5 B$ ) is shown for comparison $(\boldsymbol{F})$. A dotted red line indicates the average neurite outgrowth value in animals at $7 \mathrm{~d}$ after preconditioning SNI with PBS that were generated for the experiments in Figure $5 \mathrm{~A}-\mathrm{C}$. $\mathbf{G}$, A quantification graph of the mean neurite outgrowth per neuron in each group. ${ }^{* *} p<$ 0.001 by one-way ANOVA, followed by Tukey's post hoc analysis. $n=3$ independent experiments for each group. $\boldsymbol{H}, \mathrm{A}$ time schedule for the delayed minocycline infusion experiment. trinsic regenerative capacity is supposed to be fully elevated, almost completely abolished the SNI-induced enhanced regenerative capacity (Fig. $8 K, L$ ). The above data suggest that the maintenance of enhanced regenerative capacity for a long period may require macrophages and inflammatory reactions.

\section{Intraganglionic cAMP analog administration increased the} number of macrophages in the DRGs

It has been documented that intraganglionic elevation of cAMP mimics a conditioning injury by enhancing the intrinsic potential of axons to regenerate (Neumann et al., 2002; Qiu et al., 2002). We explored the possibility that activated macrophages may also be involved in the CAMP-induced enhancement of regenerative capacity by injecting the cAMP analog db-cAMP directly into the L5 DRG. The number of Iba1-positive macrophages was counted at $7 \mathrm{~d}$ after injection. To our surprise, injection of db-cAMP increased the number of macrophages to an extent similar to that observed after preconditioning SNI (Fig. 9B-D), whereas injection of PBS did not change the macrophage number (Fig. 9A; compared with the number in Fig. $1 G$ ). To test whether macrophages play an essential role in the CAMP-induced conditioning effects, minocycline or PBS was infused via osmotic minipumps for $7 \mathrm{~d}$ after the db-cAMP injection into the L5 DRGs. In accordance with the previous reports (Neumann et al., 2002; Qiu et al., 2002), L5 DRGs injected with db-cAMP showed enhanced neurite outgrowth comparable with that observed with preconditioning SNI (Fig. 9E-G). Minocycline infusion after db-cAMP injection completely abolished the enhanced neurite outgrowth by db-cAMP (Fig. 9H,I), suggesting that macrophage activation is essential for the cAMPinduced increase in regenerative capacity.

\section{Neuron-macrophage interactions are required for the cAMP} induction of a proregenerative phenotype in macrophages Activated macrophages produce soluble factors that potentiate neurite outgrowth of cultured neurons (Yin et al., 2003). In agreement with this, DRG neurons showed markedly enhanced neurite outgrowth when exposed to CM obtained from cultured peritoneal macrophages treated with zymosan (Fig. 10 A, B). Cotreatment of macrophages with zymosan and minocycline produced CM with almost completely abrogated growth-promoting effects (Fig. 10C), corroborating our contention that minocycline inhibits axon growth by modulation of macrophages and not by directly influencing axons. We next examined whether cAMP can instruct cultured macrophages to release proregenerative factors into culture media. CM from db-cAMP-treated macrophages elicited little enhancement of neurite outgrowth (Fig. 10D,E). The extent of increase in neurite outgrowth was negligible compared with the robust increase induced by CM from zymosantreated macrophages (Fig. 10J), indicating that cAMP does not directly activate macrophages to produce proregenerative factors. This result may indicate that cAMP primarily acts on neurons rather than macrophages and that neurons exposed to cAMP play a role in driving macrophages to a proregenerative phenotype. To evaluate the possibility that neuron-macrophage interactions are involved in the growth-promotion effects, CM

$\leftarrow$

$\boldsymbol{I}-\boldsymbol{K}$, Representative images of cultured DRG neurons from sham control (I), SNI with PBS $(\boldsymbol{J})$, and SNI with minocycline infusion groups $(\boldsymbol{K}) . \boldsymbol{L}$, A quantification graph of the mean neurite length per neuron in each group. ${ }^{* * *} p<0.001$ by one-way ANOVA, followed by Tukey's post hoc analysis. $n=3$ independent experiments for each group. Scale bars, $100 \mu \mathrm{m}$. 

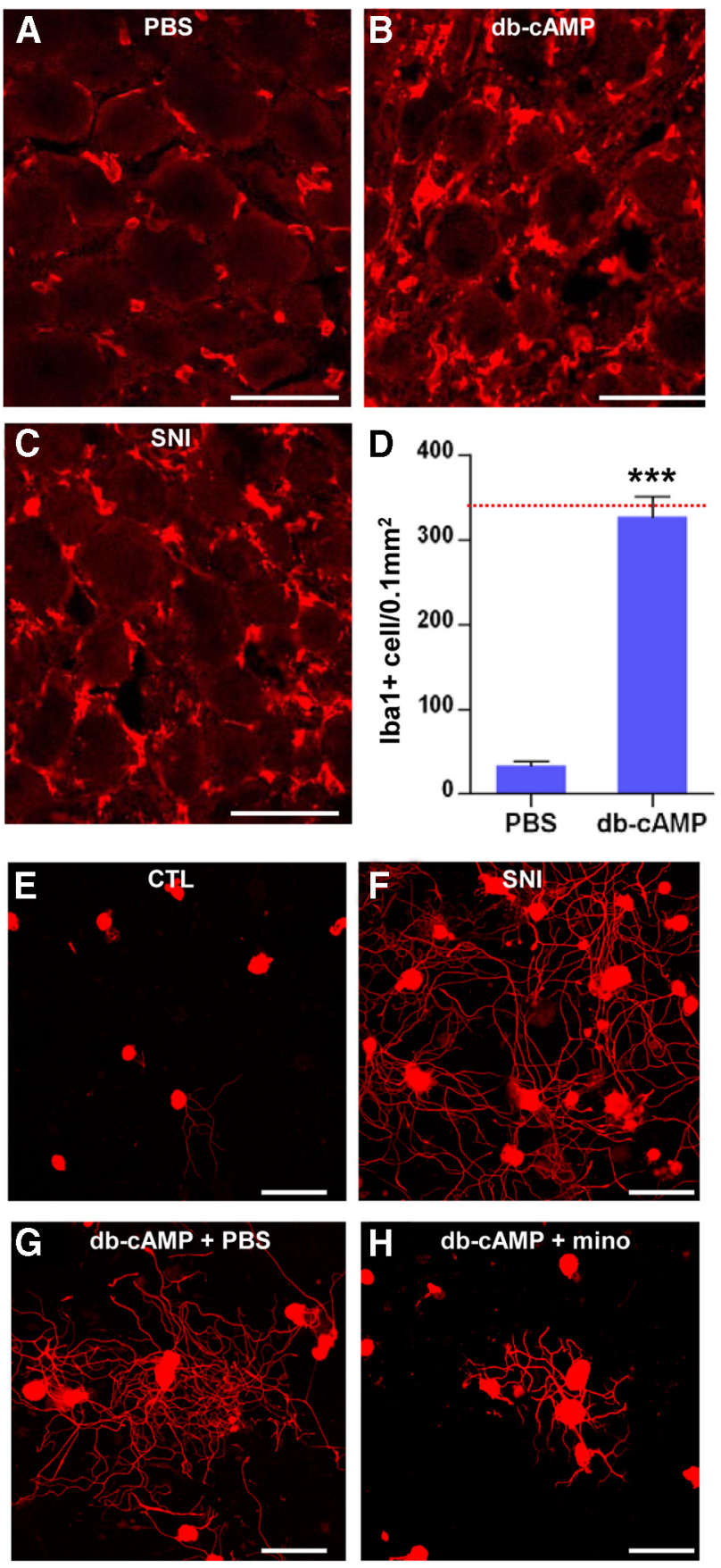

I

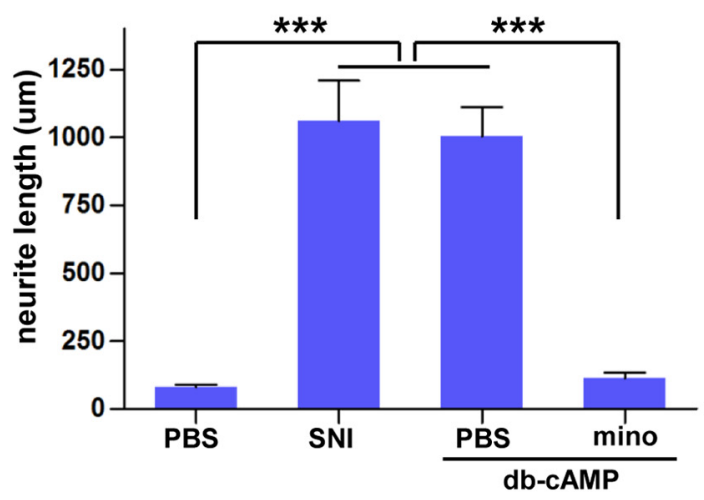

Figure 9. Intraganglionic CAMP analog injection increased the number of macrophages. A-C, Immunofluorescence images of DRG sections stained with lba1 antibody. L5 DRGs were from neuron-macrophage cocultures treated with db-cAMP was added to fresh DRG neuron cultures. In stark contrast to the lack of proregenerative effects of CM from db-cAMP-treated macrophage-only cultures, CM obtained from db-cAMP-treated neuron-macrophage cocultures increased neurite outgrowth (Fig. 10G) to an extent similar to the increase induced by CM from zymosan-treated macrophages (Fig. 10J). This effect was again abrogated by adding minocycline (Fig. 10H), suggesting that the final effectors in this setting were activated macrophages. CM from neuron-macrophage cocultures without db-cAMP did not show any effect (Fig. 10F). We found that SNI-induced macrophages physically associate with DRG neurons, and the close proximity between the two cell types was prevented by minocycline infusion (Fig. $4 A-C$, insets). To examine whether the proregenerative activity in the $\mathrm{CM}$ obtained from $\mathrm{db}$-cAMP-treated neuron-macrophage cocultures requires direct physical contacts between the two cell types, macrophages were grown on cell culture inserts, whereas neurons were cultured on the bottom of the same culture wells. The CM obtained from the cocultures with cell culture inserts promoted neurite outgrowth to a similar extent (data not shown), indicating that the neuron-macrophage interactions can be mediated by soluble factors without physical contacts between neurons and macrophages. There was no proregenerative effect of $\mathrm{CM}$ from db-cAMP-treated neuron-only cultures (Fig. 10I), further highlighting the requirement of neuron-macrophage interactions for cAMP to induce a proregenerative phenotype in macrophages.

The above experiment showed that CM obtained from cAMPtreated neuron-macrophage cocultures possessed potent proregenerative activity. To examine which molecules constitute proregenerative activity in the CM, neutralizing antibodies against neuropoietic cytokines (IL-6 and LIF) and oncomodulin were added to the CM during neurite outgrowth assays. Neutralization of either IL- 6 or LIF did not significantly reduce the extent of neurite outgrowth (Fig. $11 A-F$ ). In contrast, oncomodulin neutralizing antibody profoundly reduced neurite outgrowth (almost $80 \%$ ) (Fig. 11G-I). In accordance with this result, ELISA measurement revealed a sharp increase in oncomodulin concentration in the $\mathrm{CM}$ obtained from the cocultures treated with cAMP compared with that in the CM from the cocultures treated with control PBS. The concentration of oncomodulin in the CM from cAMP-treated cocultures was comparable with that in the CM obtained from macrophage culture treated with zymosan, the condition that was reported to induce oncomodulin production (Yin et al., 2006). These results indicate that oncomodulin may be a major proregenerative factor in the CM obtained from cAMP-treated neuron-macrophage cocultures.

\footnotetext{
$\leftarrow$

obtained $7 \mathrm{~d}$ after intraganglionic PBS (A) or db-CAMP injection ( $100 \mathrm{~mm}, 2 \mu \mathrm{l} ; \boldsymbol{B})$. C, An image of a DRG obtained after with preconditioning $\mathrm{SNI}$ (7 d) is shown for comparison. Scale bars, 50 $\mu \mathrm{m}$. $\boldsymbol{D}$, A quantification graph comparing the mean number of Iba1-positive macrophages between the DRGs with PBS or db-cAMP injection. $n=5$ animals per group. A red line marks the value of the mean macrophage number $7 \mathrm{~d}$ after preconditioning SNI (Fig. 1G). ${ }^{* *} p<0.001$ compared with PBS control value by one-way ANOVA, followed by Tukey's post hoc analysis. $\boldsymbol{E}-\boldsymbol{H}$, Representative images of DRG neurite outgrowth assays. L5 DRGs were obtained from animals without any manipulation [control (CTL); $\boldsymbol{E}]$, with preconditioning SNI $7 \mathrm{~d}$ earlier $(\boldsymbol{F})$, or with db-CAMP injection to the L5 DRGs together with infusion of PBS (G) or minocycline (mino; H). Scale bars, $100 \mu \mathrm{m}$. I, A quantification graph of the mean neurite length of cultured DRG neurons in the designated experimental groups. $n=3$ independent cultures from three separate animals for each group. ${ }^{* * *} p<0.001$ by one-way ANOVA, followed by Tukey's post hoc analysis.
} 

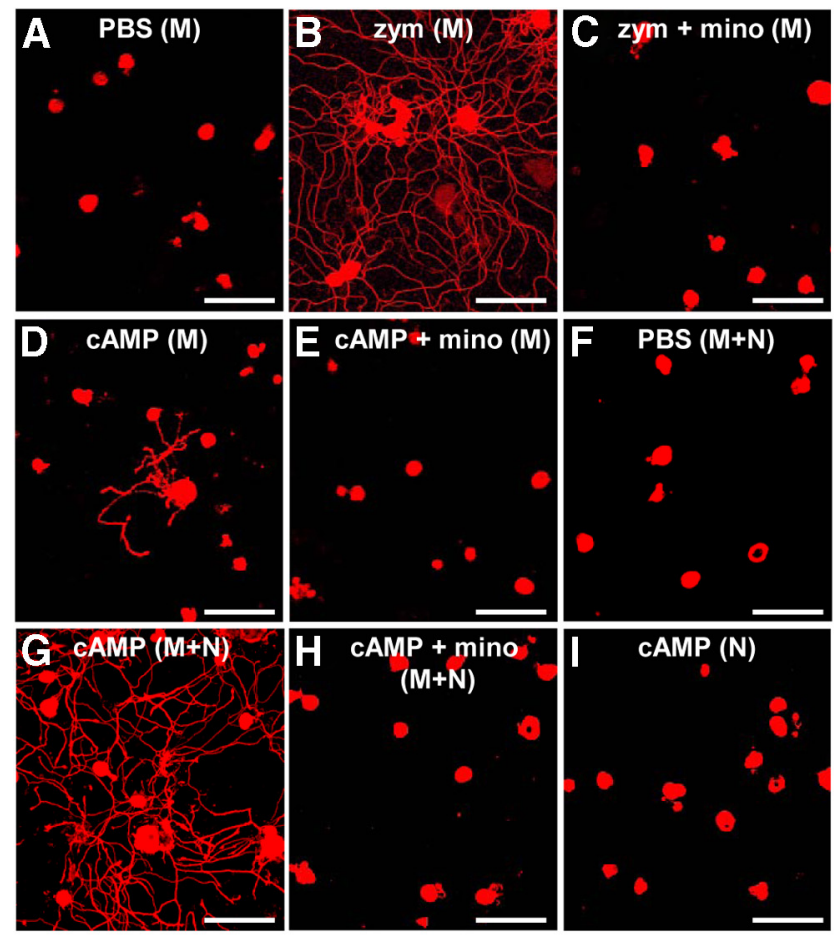

$\mathbf{J}$

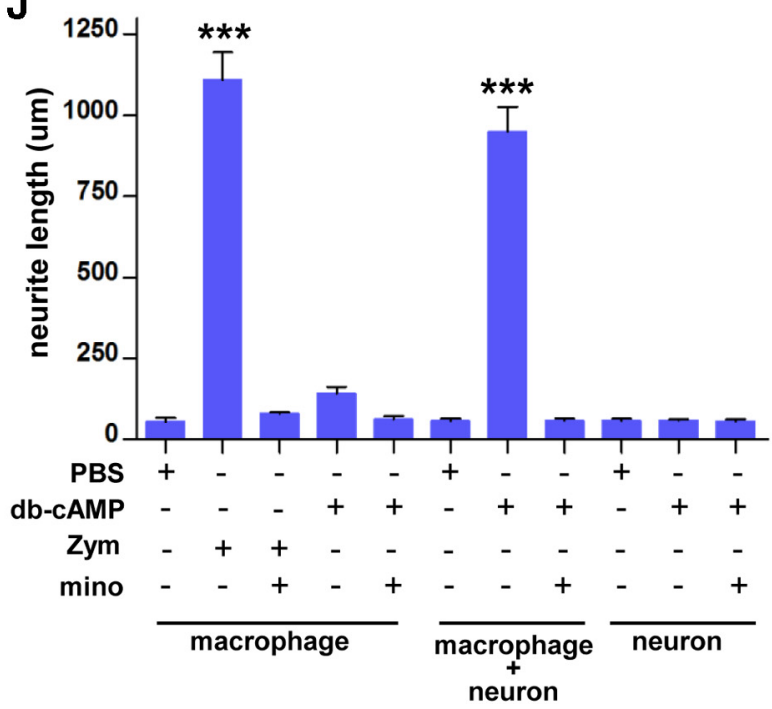

Figure 10. Neuron-macrophage interactions are required for the cAMP induction of proregenerative phenotype in macrophages. $\boldsymbol{A}-\boldsymbol{I}$, Representative images of $\beta$ III-tubulin-positive cultured DRG neurons using $C M$ collected aftervarious treatments. Peritoneal macrophages (designated as $M$ ) were treated with PBS $(\boldsymbol{A})$, zymosan $(z y \mathrm{~m}$, at $1.25 \mathrm{mg} / \mathrm{ml})$ with $(\boldsymbol{C})$ or without $(\boldsymbol{B})$ minocycline (mino, 10 $\mu \mathrm{g} / \mu \mathrm{l})$, and db-CAMP (CAMP, $100 \mu \mathrm{m}$ ) with $(\boldsymbol{E})$ or without (D) minocycline. Neuron (adult DRG neurons) and peritoneal macrophage cocultures (designated as $\mathrm{M}+\mathrm{N}$ ) were treated with $\mathrm{PBS}(\boldsymbol{F})$ or cAMP with $(\boldsymbol{H})$ or without $(\boldsymbol{G})$ minocycline. Adult DRG neuron-only cultures (designated as $\mathrm{N}$ ) were treated with cAMP $(\boldsymbol{I})$. All treatments were done for $24 \mathrm{~h}$, then the culture medium was changed, and the CM was collected $3 \mathrm{~d}$ later. The collected $C M$ was added to the DRG neuron cultures, and the cells were fixed at $15 \mathrm{~h}$ after plating. Scale bars, $100 \mu \mathrm{m}$. J, A quantification graph of the mean neurite outgrowth per neuron in different groups with different conditions of $\mathrm{CM}$ added to the cultures consisting of macrophages only, macrophage plus neurons, or neurons only. ${ }^{* * *} p<0.001$ by one-way ANOVA, followed by Tukey's post hoc analysis. $n=3$ or 4 independent cultures for each condition.

\section{Discussion}

The present study used a pharmacological approach to locally deactivate macrophages in the DRGs. The local minocycline infusion on L5 DRGs did not influence the density of Iba1-positive macrophages in the sciatic nerve or spinal cord lesion site (Fig.
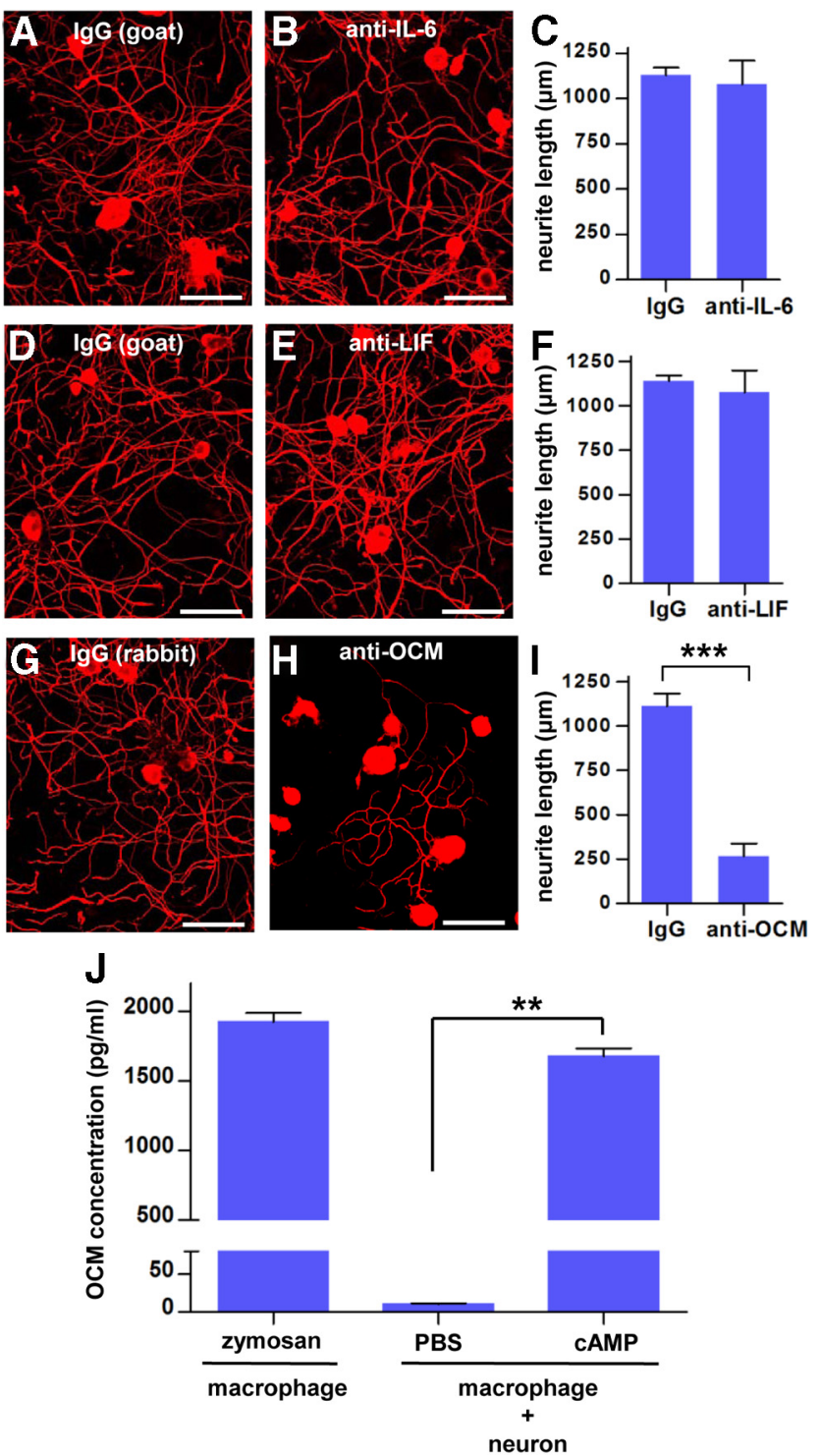

Figure 11. Neutralization of oncomodulin attenuated the CAMP-mediated proregenerative activity of CM. Representative images of $\beta$ III-tubulin-positive cultured DRG neurons treated with CM obtained from neuron-macrophage coculture. During the DRG neuron culture, neutralizing antibodies or species-matched control IgG from the same species as for the neutralizing antibodies were added to the $C M$. All CM were collected $3 \mathrm{~d}$ after replacing the medium at the end of the $24 \mathrm{~h}$ treatment with CAMP. A, B, Goat lgG and goat anti-IL-6. D, E, Goat lgG and goat anti-LIF. G, H, Rabbit IgG and rabbit anti-oncomodulin (OCM). All neutralizing and control IgGs were presented at a concentration of $20 \mu \mathrm{g} / \mathrm{ml}$. Cultured DRG neurons were fixed at $15 \mathrm{~h}$ after plating. Scale bars, $100 \mu \mathrm{m} . C, F, I$, Quantification graphs for the experiments with neutralization of IL-6 $6(\boldsymbol{C})$, LIF $(\boldsymbol{F})$, and oncomodulin (I). Only neutralization of oncomodulin resulted in a significant reduction of neurite outgrowth. $n=3$ or 4 independent cultures for each condition. J, ELISA measurement of oncomodulin concentration in the CM obtained from different conditions. $n=3$ independent cultures for each condition. ${ }^{* *} p<0.05$ and ${ }^{* * *} p<$ 0.001 by unpaired $t$ test.

$4 E, F)$, changes that could have affected the outcome of axon regeneration (Barrette et al., 2008; Horn et al., 2008; Gensel et al., 2009, 2012). In particular, excessive inflammation at the injury site is considered as a main culprit for secondary tissue degeneration after contusive SCI (Donnelly and Popovich, 2008). Recent studies also revealed that activated macrophages near injured axons induce long-distance axonal dieback (Horn et al., 2008). Indeed, containing inflammation at the lesion site by minocycline, along with its neuroprotective properties, was effective in 
A

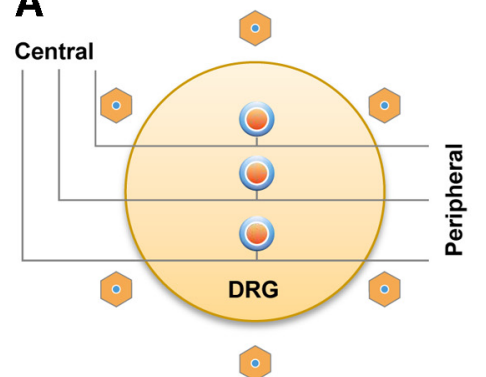

B

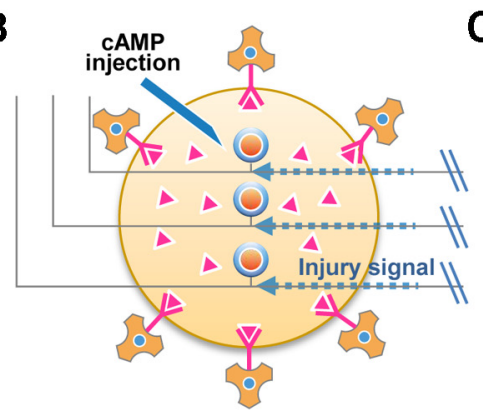

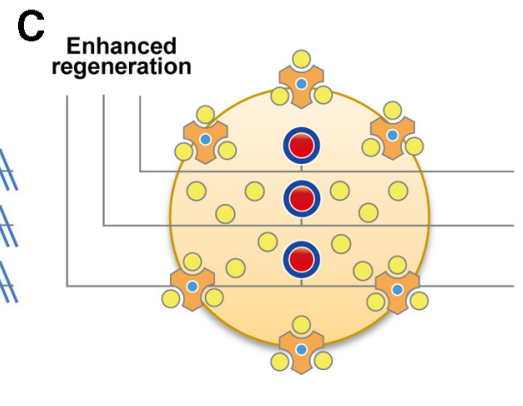

\begin{tabular}{|l|l|l|l|l|l|l|l}
\hline Activated macrophages & $\begin{array}{l}\text { Putative neuron-derived } \\
\text { molecules }\end{array}$ & $\begin{array}{l}\text { Macrophage-derived } \\
\text { proregenerative factors }\end{array}$ \\
DRG neurons $\bigcirc \begin{array}{l}\text { Neurons with enhanced } \\
\text { regenerative capacity }\end{array}$ & $\begin{array}{l}\text { Receptors for the putative } \\
\text { molecule }\end{array}$ \\
\hline
\end{tabular}

Figure 12. A schematic diagram of our model for the neuron-macrophage interactions in conditioning injury-induced enhanced regenerative capacity of DRG sensory neurons. $A$, A simplified illustration of the major players in a resting state. $\boldsymbol{B}$, Preconditioning peripheral nerve injury or CAMP injection, either of which supports activation of regeneration-associated genes, stimulates neurons to produce molecules to attract and activate macrophages. $C$, Activated macrophages produce various molecular factors that enhance regenerative capacity of DRG neurons. Our in vitro experiments suggest that oncomodulin may constitute the major proregenerative activity derived from macrophages, but the possibility remains that more molecules, such as neurotrophic factors, are also involved.

preventing secondary degeneration and promoting functional recovery (Stirling et al., 2004; Teng et al., 2004). A recent study reported promising results of a phase II clinical trial of minocycline for acute SCI (Casha et al., 2012). Our results showed that activation of macrophages and inflammatory reactions near neuronal cell bodies can be beneficial to enhancing regenerative capacity and that reducing inflammation at the cell body level may produce outcomes completely opposite to those intended when manipulating inflammation at the injury site. Therefore, we propose that potentially detrimental effects of reducing inflammation on axon regeneration must be considered when designing systemic anti-inflammatory therapeutics for SCI.

Previous studies have shown that provoking inflammation exogenously in DRGs can enhance axon regeneration. For example, Lu and Richardson (1991) reported that injection of bacterial products in DRGs induced a brisk inflammatory response and enhanced regeneration through injured dorsal root. In this study, we demonstrated for the first time that endogenously activated macrophages play essential roles in the enhancement of regenerative capacity induced by conditioning injury. Minocycline administration decreased macrophage numbers and lowered expression of inflammatory mediators and completely abolished SNI-induced conditioning effects in vitro and significantly attenuated them in vivo. Notably, preconditioning SNI-induced prevention of axon retraction was not significantly influenced by minocycline, whereas axon regeneration past the lesion site was effectively blocked. This is in agreement with the suggestion that the requirements to promote axon regeneration past the lesion site and to overcome axonal dieback may differ (Horn et al., 2008).

We observed a gradual increase in macrophage number over several days after SNI, with a peak at $7 \mathrm{~d}$. Enhanced neurite outgrowth was observed at $1 \mathrm{~d}$ after preconditioning SNI, when the number of macrophages was not increased yet. Previous studies also reported that proregenerative responses by SNI develop as early as $1 \mathrm{~d}$ after injury (Qiu et al., 2002; Zou et al., 2009). Our observation that minocycline infusion for $1 \mathrm{~d}$ did not prevent the enhanced neurite outgrowth is consistent with a notion that retrograde injury signals trigger regenerative neurite outgrowth induced by conditioning injury (Hanz et al., 2003). The almost complete abrogation of the SNI-induced enhanced neurite out- growth by minocycline for the $3 \mathrm{~d}$ duration indicates that macrophages may be required for the evolution of the injurytriggered conditioning effects to a full manifestation. At this $3 \mathrm{~d}$ time point, neurite outgrowth was almost fully enhanced, whereas the increase in macrophage number was still modest. We speculate that even the modest degree of macrophage activation may be sufficient to almost fully elevate growth potential of DRG neurons recently primed by conditioning injury. More importantly, our data suggest that macrophages seem to be essential for maintaining the SNI-induced enhanced regenerative capacity chronically because deactivation of macrophages by minocycline infusion after the full manifestation of conditioning effects almost completely abrogated the neurite outgrowth. Thus, the increases in macrophage number persisting for at least 1 month may be a part of the mechanism underlying the enhanced regenerative potential of chronically preconditioned DRG neurons (Ylera et al., 2009).

We also found that an injury to the central branch (rhizotomy) was not associated with an increase in macrophage number. A lack of macrophage activation by central axotomy might lead to a failure in the maintenance of long-lasting regenerative processes. It has been reported that central axotomy can transiently upregulate regeneration-associated genes if axons are severed close to the cell body (Fernandes et al., 1999). Deficient macrophage activation near the cell body after central axotomy might have resulted in the failure of prolonged activation of the regeneration program in this circumstance. Therefore, a lack of macrophage activation in CNS neurons could contribute in part to a failure of CNS axon regeneration. However, activation of macrophages does not seem to be sufficient to promote significant CNS axon regeneration. Chemically induced macrophage activation near neuronal cell bodies failed to induce robust axon growth of injured (root crush) sensory axons past the dorsal root entry zone (Steinmetz et al., 2005) or did not promote regeneration of the corticospinal tract after cervical axotomy (HossainIbrahim et al., 2006). The finding that macrophage activation only when combined with local application of chondroitinase achieved significant regeneration (Steinmetz et al., 2005) suggests that the extent of enhancement in regenerative capacity by activation of macrophages may not be sufficient to overcome hostile local environment. 
It is not known exactly how activated macrophages enhance axonal regeneration (Filbin, 2006; Fischer, 2010). We found upregulations of the neuropoietic cytokines IL-6 and LIF, both of which have been demonstrated to play a role in axon regeneration (Cafferty et al., 2001, 2004). Interestingly, the time course of IL-6 and LIF upregulation closely matched that of the macrophage increase (Fig. $2 A-C$ ), suggesting a contribution of macrophages in the production of these inflammatory cytokines. Indeed, RTPCR analysis of the CD68-positive fraction from dissociated DRG cells demonstrated that IL-6 and LIF expressions occurred in this macrophage fraction. However, neutralization of either IL-6 or LIF failed to significantly attenuate proregenerative activity in the CM collected from cAMP-treated neuron-macrophage cocultures. We also found a significant upregulation of oncomodulin in DRGs after conditioning SNI. Neutralizing antibody against oncomodulin suppressed proregenerative activity in the CM by $>80 \%$. These findings indicate that enhanced axonal regeneration by activated macrophages is principally mediated by oncomodulin but not by IL-6 or LIF, at least in our coculture condition. We also observed SNI-induced increase of various neurotrophins in DRGs. Macrophage-produced neurotrophins may contribute to the remaining proregenerative activity in the CM.

Intraganglionic injection of cAMP, which was shown to mimic conditioning effects (Neumann et al., 2002; Qiu et al., 2002), also increased the number of macrophages in the DRGs. Minocycline abrogated the cAMP effects as well, indicating that macrophages are also essential for the cAMP-mediated enhancement of intrinsic regenerative potential. These findings suggest that the activation of macrophages with a proregenerative phenotype in DRGs is not specifically related to peripheral nerve injury but may be a general phenomenon after an increase in intrinsic regenerative capacity in neurons. In this context, preconditioning SNI or cAMP treatment would not directly activate proregenerative programs in macrophages. Indeed, CM from macrophages treated with cAMP did not significantly promote neurite outgrowth of cultured DRG neurons. This finding suggests that the cAMP could not directly instruct macrophages to produce axon growth-promoting factors and that other cell types, most likely neurons, may be required to turn on the proregenerative phenotype in macrophages. In accordance with this, $\mathrm{CM}$ obtained from neuron-macrophage cocultures treated with cAMP promoted neurite outgrowth to an extent comparable with $\mathrm{CM}$ from macrophages treated with zymosan. In contrast, $\mathrm{CM}$ obtained from neuron-only cultures treated with cAMP did not affect neurite outgrowth. This suggests that cAMP-activated neurons stimulate macrophages to acquire a proregenerative phenotype but do not directly produce factors promoting axon growth.

This notion may also be applicable to the SNI-induced enhanced regenerative capacity of DRG neurons (Fig. 12A-C). A retrogradely transmitted injury signal (Hanz and Fainzilber, 2006) could trigger upregulation of regeneration-associated genes in neurons (Hoffman, 2010). Then, injury-triggered transcriptional activity in neurons could stimulate neighboring macrophages to acquire a proregenerative phenotype (Fig. 12B). It has been reported that CNS-specific deletion of the transcription factor c-Jun, one of the well characterized regenerationassociated genes (Broude et al., 1999), results in a defect in microglial activation (Raivich et al., 2004). Our coculture experiment using cell culture inserts suggested that neurons may produce soluble factors that influence macrophages. The activated macrophages may play significant roles in prolonged main- tenance of enhanced regenerative potentials by supplying proregenerative factors to neurons (Fig. 12C). Thus, our study suggests that the neuron-macrophage interactions are required to link injury-triggered neuronal responses with proregenerative macrophage activation, culminating in long-lasting regenerative processes after preconditioning peripheral nerve injury.

Promoting regeneration of injured CNS axons is a prime target for research aiming to improve functional recovery after CNS injury. Based on the results of this study, we suggest that a lack of sufficient macrophage activation in response to CNS axonal damages may be responsible in part for the inability to mount long-lasting regenerative processes. Thus, future studies into the neuron-macrophage interactions that link injury signals to proregenerative macrophage activity will provide new insights for developing axon regeneration therapeutics.

\section{References}

Arnold SA, Hagg T (2011) Anti-inflammatory treatments during the chronic phase of spinal cord injury improve locomotor function in adult mice. J Neurotrauma 28:1995-2002. CrossRef Medline

Barouch R, Appel E, Kazimirsky G, Brodie C (2001) Macrophages express neurotrophins and neurotrophin receptors. Regulation of nitric oxide production by NT-3. J Neuroimmunol 112:72-77. CrossRef Medline

Barrette B, Hébert MA, Filali M, Lafortune K, Vallières N, Gowing G, Julien JP, Lacroix S (2008) Requirement of myeloid cells for axon regeneration. J Neurosci 28:9363-9376. CrossRef Medline

Benowitz LI, Routtenberg A (1997) GAP-43: an intrinsic determinant of neuronal development and plasticity. Trends Neurosci 20:84-91. CrossRef Medline

Broude E, McAtee M, Kelley MS, Bregman BS (1999) Fetal spinal cord transplants and exogenous neurotrophic support enhance c-Jun expression in mature axotomized neurons after spinal cord injury. Exp Neurol 155:65-78. CrossRef Medline

Cafferty WB, Gardiner NJ, Gavazzi I, Powell J, McMahon SB, Heath JK, Munson J, Cohen J, Thompson SW (2001) Leukemia inhibitory factor determines the growth status of injured adult sensory neurons. J Neurosci 21:7161-7170. Medline

Cafferty WB, Gardiner NJ, Das P, Qiu J, McMahon SB, Thompson SW (2004) Conditioning injury-induced spinal axon regeneration fails in interleukin-6 knock-out mice. J Neurosci 24:4432-4443. CrossRef Medline

Cafferty WB, McGee AW, Strittmatter SM (2008) Axonal growth therapeutics: regeneration or sprouting or plasticity? Trends Neurosci 31:215-220. CrossRef Medline

Cai D, Deng K, Mellado W, Lee J, Ratan RR, Filbin MT (2002) Arginase I and polyamines act downstream from cyclic AMP in overcoming inhibition of axonal growth MAG and myelin in vitro. Neuron 35:711-719. CrossRef Medline

Cao Z, Gao Y, Bryson JB, Hou J, Chaudhry N, Siddiq M, Martinez J, Spencer T, Carmel J, Hart RB, Filbin MT (2006) The cytokine interleukin-6 is sufficient but not necessary to mimic the peripheral conditioning lesion effect on axonal growth. J Neurosci 26:5565-5573. CrossRef Medline

Casha S, Zygun D, McGowan MD, Bains I, Yong VW, Hurlbert RJ (2012) Results of a phase II placebo-controlled randomized trial of minocycline in acute spinal cord injury. Brain 135:1224-1236. CrossRef Medline

Chong MS, Reynolds ML, Irwin N, Coggeshall RE, Emson PC, Benowitz LI, Woolf CJ (1994) GAP-43 expression in primary sensory neurons following central axotomy. J Neurosci 14:4375-4384. Medline

Donnelly DJ, Popovich PG (2008) Inflammation and its role in neuroprotection, axonal regeneration and functional recovery after spinal cord injury. Exp Neurol 209:378-388. CrossRef Medline

Fernandes KJ, Fan DP, Tsui BJ, Cassar SL, Tetzlaff W (1999) Influence of the axotomy to cell body distance in rat rubrospinal and spinal motoneurons: differential regulation of GAP-43, tubulins, and neurofilament-M. J Comp Neurol 414:495-510. CrossRef Medline

Filbin MT (2006) How inflammation promotes regeneration. Nat Neurosci 9:715-717. CrossRef Medline

Fischer D (2010) What are the principal mediators of optic nerve regeneration after inflammatory stimulation in the eye? Proc Natl Acad Sci U S A 107:E8; author reply E9. CrossRef Medline 
Gensel JC, Nakamura S, Guan Z, van Rooijen N, Ankeny DP, Popovich PG (2009) Macrophages promote axon regeneration with concurrent neurotoxicity. J Neurosci 29:3956-3968. CrossRef Medline

Gensel JC, Kigerl KA, Mandrekar-Colucci SS, Gaudet AD, Popovich PG (2012) Achieving CNS axon regeneration by manipulating convergent neuro-immune signaling. Cell Tissue Res 349:201-213. CrossRef Medline

Ghanouni P, Behera D, Xie J, Chen X, Moseley M, Biswal S (2012) In vivo USPIO magnetic resonance imaging shows that minocycline mitigates macrophage recruitment to a peripheral nerve injury. Mol Pain 8:49. CrossRef Medline

Hanz S, Fainzilber M (2006) Retrograde signaling in injured nerve-the axon reaction revisited. J Neurochem 99:13-19. CrossRef Medline

Hanz S, Perlson E, Willis D, Zheng JQ, Massarwa R, Huerta JJ, Koltzenburg M, Kohler M, van-Minnen J, Twiss JL, Fainzilber M (2003) Axoplasmic importins enable retrograde injury signaling in lesioned nerve. Neuron 40:1095-1104. CrossRef Medline

Hauk TG, Müller A, Lee J, Schwendener R, Fischer D (2008) Neuroprotective and axon growth promoting effects of intraocular inflammation do not depend on oncomodulin or the presence of large numbers of activated macrophages. Exp Neurol 209:469-482. CrossRef Medline

Hoffman PN (2010) A conditioning lesion induces changes in gene expression and axonal transport that enhance regeneration by increasing the intrinsic growth state of axons. Exp Neurol 223:11-18. CrossRef Medline

Hollis ER 2nd, Zou Y (2012) Reinduced Wnt signaling limits regenerative potential of sensory axons in the spinal cord following conditioning lesion. Proc Natl Acad Sci U S A 109:14663-14668. CrossRef Medline

Horn KP, Busch SA, Hawthorne AL, van Rooijen N, Silver J (2008) Another barrier to regeneration in the CNS: activated macrophages induce extensive retraction of dystrophic axons through direct physical interactions. J Neurosci 28:9330-9341. CrossRef Medline

Hossain-Ibrahim MK, Rezajooi K, MacNally JK, Mason MR, Lieberman AR, Anderson PN (2006) Effects of lipopolysaccharide-induced inflammation on expression of growth-associated genes by corticospinal neurons. BMC Neurosci 7:8. CrossRef Medline

Leon S, Yin Y, Nguyen J, Irwin N, Benowitz LI (2000) Lens injury stimulates axon regeneration in the mature rat optic nerve. J Neurosci 20:46154626. Medline

Lu X, Richardson PM (1991) Inflammation near the nerve cell body enhances axonal regeneration. J Neurosci 11:972-978. Medline

Lu X, Richardson PM (1993) Responses of macrophages in rat dorsal root ganglia following peripheral nerve injury. J Neurocytol 22:334-341. CrossRef Medline

Nadeau S, Filali M, Zhang J, Kerr BJ, Rivest S, Soulet D, Iwakura Y, de Rivero Vaccari JP, Keane RW, Lacroix S (2011) Functional recovery after peripheral nerve injury is dependent on the pro-inflammatory cytokines IL-1beta and TNF: implications for neuropathic pain. J Neurosci 31: 12533-12542. CrossRef Medline

Neumann S, WoolfCJ (1999) Regeneration of dorsal column fibers into and beyond the lesion site following adult spinal cord injury. Neuron 23:8391. CrossRef Medline

Neumann S, Bradke F, Tessier-Lavigne M, Basbaum AI (2002) Regeneration of sensory axons within the injured spinal cord induced by intraganglionic cAMP elevation. Neuron 34:885-893. CrossRef Medline

Qiu J, Cai D, Dai H, McAtee M, Hoffman PN, Bregman BS, Filbin MT (2002) Spinal axon regeneration induced by elevation of cyclic AMP. Neuron 34:895-903. CrossRef Medline

Qiu J, Cafferty WB, McMahon SB, Thompson SW (2005) Conditioning injury-induced spinal axon regeneration requires signal transducer and activator of transcription 3 activation. J Neurosci 25:1645-1653. CrossRef Medline

Raghavendra V, Tanga F, DeLeo JA (2003) Inhibition of microglial activation attenuates the development but not existing hypersensitivity in a rat model of neuropathy. J Pharmacol Exp Ther 306:624-630. CrossRef Medline

Raivich G, Bohatschek M, Da Costa C, Iwata O, Galiano M, Hristova M, Nateri AS, Makwana M, Riera-Sans L, Wolfer DP, Lipp HP, Aguzzi A, Wagner EF, Behrens A (2004) The AP-1 transcription factor c-Jun is required for efficient axonal regeneration. Neuron 43:57-67. CrossRef Medline

Richardson PM, Issa VM (1984) Peripheral injury enhances central regeneration of primary sensory neurones. Nature 309:791-793. CrossRef Medline

Schreyer DJ, Skene JH (1993) Injury-associated induction of GAP-43 expression displays axon branch specificity in rat dorsal root ganglion neurons. J Neurobiol 24:959-970. CrossRef Medline

Schwab ME (2002) Repairing the injured spinal cord. Science 295: 1029-1031. CrossRef Medline

Steinmetz MP, Horn KP, Tom VJ, Miller JH, Busch SA, Nair D, Silver DJ, Silver J (2005) Chronic enhancement of the intrinsic growth capacity of sensory neurons combined with the degradation of inhibitory proteoglycans allows functional regeneration of sensory axons through the dorsal root entry zone in the mammalian spinal cord. J Neurosci 25:8066-8076. CrossRef Medline

Stirling DP, Khodarahmi K, Liu J, McPhail LT, McBride CB, Steeves JD, Ramer MS, Tetzlaff W (2004) Minocycline treatment reduces delayed oligodendrocyte death, attenuates axonal dieback, and improves functional outcome after spinal cord injury. J Neurosci 24:2182-2190. CrossRef Medline

Teng YD, Choi H, Onario RC, Zhu S, Desilets FC, Lan S, Woodard EJ, Snyder EY, Eichler ME, Friedlander RM (2004) Minocycline inhibits contusiontriggered mitochondrial cytochrome $\mathrm{c}$ release and mitigates functional deficits after spinal cord injury. Proc Natl Acad Sci U S A 101:3071-3076. CrossRef Medline

Yin Y, Cui Q, Li Y, Irwin N, Fischer D, Harvey AR, Benowitz LI (2003) Macrophage-derived factors stimulate optic nerve regeneration. J Neurosci 23:2284-2293. Medline

Yin Y, Henzl MT, Lorber B, Nakazawa T, Thomas TT, Jiang F, Langer R, Benowitz LI (2006) Oncomodulin is a macrophage-derived signal for axon regeneration in retinal ganglion cells. Nat Neurosci 9:843-852. CrossRef Medline

Yin Y, Cui Q, Gilbert HY, Yang Y, Yang Z, Berlinicke C, Li Z, Zaverucha-doValle C, He H, Petkova V, Zack DJ, Benowitz LI (2009) Oncomodulin links inflammation to optic nerve regeneration. Proc Natl Acad Sci U S A 106:19587-19592. CrossRef Medline

Ylera B, Ertürk A, Hellal F, Nadrigny F, Hurtado A, Tahirovic S, Oudega M, Kirchhoff F, Bradke F (2009) Chronically CNS-injured adult sensory neurons gain regenerative competence upon a lesion of their peripheral axon. Curr Biol 19:930-936. CrossRef Medline

Yong VW, Wells J, Giuliani F, Casha S, Power C, Metz LM (2004) The promise of minocycline in neurology. Lancet Neurol 3:744-751. CrossRef Medline

Zou H, Ho C, Wong K, Tessier-Lavigne M (2009) Axotomy-induced Smad1 activation promotes axonal growth in adult sensory neurons. J Neurosci 29:7116-7123. CrossRef Medline 